RAGUÉS, Ramon; BELMONTE, Matías: "El incentivo de las denuncias como instrumento

de prevención y persecución penal: presente y futuro del whistleblowing en Chile".

Polít. Crim. Vol. 16, No 31 (Julio 2021), Art. 1, pp. 1-29

[http://politcrim.com/wp-content/uploads/2021/04/Vol16N31A1.pdf]

\title{
El incentivo de las denuncias como instrumento de prevención y persecución penal: presente y futuro del whistleblowing en Chile*
}

\section{Encouraging Reports to Prevent and Prosecute Crime: Present and Future of Whistleblowing in Chile}

\author{
Ramon Ragués i Vallès \\ Catedrático de Derecho penal, Universidad Pompeu Fabra \\ ramon.ragues@upf.edu \\ https://orcid.org/0000-0002-5619-6706 \\ Matías Belmonte Parra \\ Investigador predoctoral y docente, Universidad Pompeu Fabra \\ matias.belmonte@upf.edu \\ https://orcid.org/0000-0001-6125-3739
}

\section{Resumen}

Fecha de recepción: 20/07/2020.

Fecha de aceptación: 24/09/2020.

El presente trabajo tiene como objetivo exponer cómo la tendencia global de incentivar las denuncias ciudadanas como medio de prevención y descubrimiento de delitos se está concretando en las políticas públicas y en el sistema jurídico chileno. Con tal propósito el artículo analiza cuáles son los recursos que los poderes públicos en cualquier país tienen a su alcance para lograr que los ciudadanos se sientan movidos a denunciar, así como las ventajas y desventajas de cada uno de estos estímulos. Se ofrece también una panorámica del estado de la cuestión sobre la presente materia en Chile y una valoración de las alternativas que se presentan a las autoridades chilenas en este ámbito.

Palabras clave: whistleblowing, denuncias, protección a los denunciantes.

\begin{abstract}
This paper exposes how the global trend of encouraging citizen report for crime prevention and discovery is taking shape in public policies and in the Chilean justice system. This article analyzes the resources that the State and its agencies in any country have at their disposal to promote citizens to denounce, as well as the advantages and disadvantages of each of these

\footnotetext{
* La redacción del presente trabajo se enmarca en la ejecución del proyecto de investigación "La transformación de los principios limitadores del ius puniendi en el moderno Derecho penal económico y de la empresa". Referencia: DER2017-82232-P (AEI/FEDER, UE). Agradecemos la revisión y observaciones realizadas por la profesora Carolina Helfmann Martini y el profesor Rodrigo Azócar Simonet, cuyas perspectivas desde el Derecho administrativo y laboral, respectivamente, fueron muy útiles para tener una panorámica global del ordenamiento chileno. Cualquier error u omisión de referencia a dichos ámbitos es, en cualquier caso, de exclusiva responsabilidad nuestra. El texto se cerró de manera definitiva el día $1^{\circ}$ de octubre de 2020.
} 
incentives. This article also offers an overview of the state of play on the subject in Chile and an assessment of the alternatives that are presented to the Chilean authorities in this area.

Keywords: whisteblowing, reports, whistleblower protection.

\section{Introducción: una estrategia de la política criminal contemporánea}

El fomento de las denuncias ciudadanas es una de las principales estrategias de la política criminal contemporánea en la lucha contra la criminalidad corporativa y la corrupción. Según suele afirmarse, tanto la empresa como la administración pública son dos ámbitos de muy difícil penetración para las investigaciones de la policía, los fiscales o los jueces y ello tiene como consecuencia que un porcentaje muy elevado de los delitos que se cometen en estos entornos permanezca en la impunidad. Ante esta dificultad, en las últimas décadas los poderes públicos han apostado decididamente en muchos países por incentivar a los conocedores directos de estos hechos —es decir, los trabajadores en las empresas y los funcionarios en la administración - para que denuncien aquellos comportamientos ilícitos de los que tengan información. Con este objetivo, en muchas legislaciones se han previsto estímulos de diversa naturaleza, cuyo propósito es que tales sujetos venzan su desinterés o sus temores y se decidan a denunciar, convirtiéndose en lo que, en la extendida expresión inglesa, se denomina un whistleblower.

Esta figura - que en castellano suele traducirse con términos como "denunciante", "informante" o "alertador"- abarca situaciones diversas, que van desde la actuación de quien denuncia irregularidades ante su propia organización (el llamado whistleblowing interno), hasta quien decide informar directamente a las autoridades, ya sean judiciales o administrativas (whistleblowing externo), o bien acude a los medios de comunicación. En algunos casos es posible que el alertador sea un mero conocedor de las irregularidades que denuncia; pero en otros, cabe también la posibilidad de que haya intervenido en tales irregularidades. En cuanto a su objeto, las denuncias pueden referirse a delitos, pero también a infracciones administrativas o vulneraciones de códigos éticos corporativos. Finalmente, la condición de whistleblower a menudo no solo se atribuye a quien es miembro integrante de una concreta organización, sino también a personas con un vínculo más indirecto: antiguos empleados, proveedores o clientes. Todas estas particularidades son relevantes, como se verá más adelante, para analizar el tratamiento jurídico de la presente figura.

El creciente interés público en incentivar las denuncias tiene su origen en los Estados Unidos de América y, aunque cuenta con precedentes remotos, en sus antecedentes más próximos aparece asociado al fenómeno del criminal compliance de las grandes compañías. Contar con un procedimiento interno de denuncia de irregularidades es un elemento básico de todo programa de cumplimiento normativo, como demuestra una visita a la página web de cualquier empresa mínimamente relevante. A partir de este punto de inicio, el interés por incentivar las denuncias se ha extendido geográficamente hacia el resto del planeta y, desde el sector privado, se ha ido ampliando también hacia el público: ${ }^{1}$ sin ir más lejos, desde finales

\footnotetext{
${ }^{1}$ De hecho, se ha llegado a acuñar la expresión de "public compliance” para hacer referencia a la proyección de las buenas prácticas corporativas al ámbito de la administración pública. A modo de referencia, véase GUTIÉRREZ PÉREZ (2018), pp. 104-143.
} 


\section{Polít. Crim. Vol. 16, № 31 (Julio 2021), Art. 1, pp. 1-29 [http://politcrim.com/wp-content/uploads/2021/04/Vol16N31A1.pdf]}

de 2019 existe en la Unión Europea una Directiva (nos referiremos a ello en apartado 1) que impone a los Estados miembros el deber de garantizar una serie de denominadores comunes en la regulación de esta materia, tanto en las empresas como en la administración. ${ }^{2}$ Asimismo la tendencia también se observa en diversos ordenamientos jurídicos latinoamericanos, entre ellos Chile. ${ }^{3}$

El presente trabajo tiene como objetivo exponer cómo esta tendencia global se está concretando en las políticas públicas y en el sistema jurídico chileno. Con tal propósito, y después de este breve apartado introductorio, se dedicará un segundo epígrafe a exponer de modo genérico cuáles son los recursos que los poderes públicos en cualquier país tienen a su alcance para lograr que los ciudadanos se sientan movidos a denunciar, así como los pros y contras de cada uno de estos estímulos (1). A continuación, se ofrecerá una panorámica del estado de la cuestión sobre la presente materia en Chile (2). Por último, a la luz de la experiencia internacional, se dedicará un apartado final a valorar las disyuntivas con las que, con gran seguridad, se encontrarán las autoridades chilenas si siguen apostando por estas políticas de prevención (3).

\section{Los incentivos para la denuncia}

Unos poderes públicos que pretendan incentivar las denuncias tienen a su alcance diversos instrumentos con los que tratar de persuadir a aquellos sujetos que disponen de información. ${ }^{4}$ Con dichos incentivos se busca que los potenciales alertadores venzan su habitual desinterés por informar - ya sea por pensar que no es asunto suyo o no querer perder el tiempo- o superen sus naturales temores a hacerlo, debido a las represalias a las que a menudo quedan expuestos quienes deciden dar semejante paso. En la perspectiva internacional los incentivos más frecuentemente empleados son los cuatro siguientes:

a) Imposición de deberes de denuncia: esta primera opción consiste en obligar a los conocedores de infracciones penales ajenas a denunciarlas bajo amenaza de algún tipo de sanción. Dicha imposición puede ser genérica o sectorial: una obligación genérica de denuncia se prevé en unos pocos países como, por ejemplo, España, aunque castigada con sanciones simbólicas. ${ }^{5}$ En muchos ordenamientos se observa, en cambio, la creciente

\footnotetext{
${ }^{2}$ En cuanto al panorama europeo, en particular en el ámbito de la corrupción previo a la referida Directiva, véase BENITO (2019), pp. 520-548, quien da cuenta de que uno de los desafíos más importantes es la implementación de las políticas europeas en cada Estado miembro.

${ }^{3}$ En este sentido, en Chile también es posible constatar cómo el compliance ha sido el primer ámbito donde modernamente ha aparecido la figura del whistleblower. En efecto, la Ley 20.393, de responsabilidad penal de personas jurídicas, permite eximir de responsabilidad a aquellas entidades que hayan cumplido con sus deberes de dirección y supervigilancia, entre los que figura la adopción e implementación de un modelo de organización, administración y supervisión de prevención de delitos previo a la infracción. El art. $4^{\circ}$ de la referida Ley establece las condiciones de estos modelos de prevención, entre los cuales se menciona la verificación de “procedimientos de denuncia". Sobre la aplicación práctica de la Ley 20.393, véase NAVAS y JAAR (2018), pp. 1027-1054.

${ }^{4}$ En VANDEKERCKHOVE y TSAHURIDU (2010), p. 372, se denomina la tendencia a la generación de incentivos en este sentido como mecanismos de "easy whistleblowing".

${ }^{5}$ El art. 259 de la Ley de Enjuiciamiento Criminal dispone que "el que presenciare la perpetración de cualquier delito público está obligado a ponerlo inmediatamente en conocimiento del Juez de instrucción, de Paz, Comarcal o Municipal, o Funcionario fiscal más próximo al sitio en que se hallare, bajo la multa de 25 a 250
} 
tendencia a imponer deberes específicos de denuncia a personas que, por su profesión o actividad, suelen estar en contacto con hechos ilícitos (los llamados gatekeepers) o tienen deberes especiales hacia la administración. Tal es el caso, por ejemplo, del personal sanitario respecto de ciertos delitos violentos o sexuales, de los empleados de entidades bancarias o financieras en el caso del lavado o, en general, de los funcionarios públicos, aunque no tengan la competencia específica de perseguir delitos. ${ }^{6}$

Las dudas que suscita esta opción son varias: la principal es que parece complicado justificar la imposición de una obligación de denuncia basada en el deber de contribuir activamente a un mejor funcionamiento de la Administración de Justicia en sistemas que se auto conciben como liberales y que, por lo general, castigan muy moderadamente la infracción de los deberes de solidaridad mínima, normalmente solo cuando están en riesgo bienes jurídicos personales de primer orden. Prever castigos realmente disuasorios para la infracción del deber de denuncia y hacerlo con coherencia sistemática no parece posible sin una modificación radical en la valoración de la importancia de los deberes basados en la solidaridad. De tal modo que, si quisiera llevarse realmente a la práctica un modelo que sancionara con severidad el incumplimiento del deber de denuncia, la consecuencia más probable sería un Derecho penal en general mucho más severo, pues, para evitar el sinsentido que supondría imponer castigos similares a quien comete una infracción y a quien solo deja de denunciarla, la pena del primero debería incrementarse sensiblemente.

Ciertamente, la sanción del incumplimiento del deber de denuncia puede preverse solo en términos simbólicos, pero, como demuestra el ejemplo español, en tal caso su capacidad motivadora es prácticamente nula. En realidad, la previsión de un deber de denuncia sancionado simbólicamente solo tiene una ventaja en tanto que incentivo: otorgar al denunciante una causa de justificación en aquellos casos en los que, al denunciar, el alertador revela informaciones protegidas por algún tipo de deber de confidencialidad. Es decir, el cumplimiento del deber actúa como una cláusula de protección frente a posibles acciones judiciales que la propia empresa pueda emprender contra su denunciante. Pero, como se verá más adelante, este mismo efecto puede conseguirse también por otras vías.

b) Promesa de recompensas económicas: se trata de un recurso por el que se ha apostado tradicionalmente en los Estados Unidos, mientras que en los países de la Europa continental apenas se ha utilizado. Allí desde 1863 la False Claims Act federal prevé la concesión a los informantes de un porcentaje — que puede llegar al 30\%- de las cantidades que el Estado recupere gracias a las denuncias. ${ }^{7}$ Esta ley, en sus más de ciento cincuenta años de vigencia,

pesetas". Esta previsión, pensada para los testigos directos del hecho, se complementa con el art. 264 de la misma Ley, que dispone que "el que por cualquier medio diferente de los mencionados tuviere conocimiento de la perpetración de algún delito de los que deben perseguirse de oficio, deberá denunciarlo al Ministerio fiscal, al Tribunal competente o al Juez de instrucción o municipal, o funcionario de policía, sin que se entienda obligado por esto a probar los hechos denunciados ni a formalizar querella". Un precepto este último que impone un deber de denuncia a los llamados "testigos de referencia", para cuyo incumplimiento no se impone sanción alguna, a diferencia de lo previsto por el primer artículo para aquellos casos en los que el potencial denunciante ha sido testigo directo de los hechos

${ }^{6}$ Sobre este fenómeno, especialmente en los Estados Unidos, GUERRA (2002), pp. 3-65.

${ }^{7}$ Referencias concretas sobre recompensas otorgadas a informantes en el Derecho estadounidense en varios autores (CALLAHAN et al. (2003-2004), pp. 896-898; CALLAHAN y DWORKIN (1992), p. 278 ss.; 


\section{Polít. Crim. Vol. 16, № 31 (Julio 2021), Art. 1, pp. 1-29 [http://politcrim.com/wp-content/uploads/2021/04/Vol16N31A1.pdf]}

ha permitido, gracias a dichas denuncias, recuperar para el erario elevadas cantidades económicas que le habían sido defraudadas. Más recientemente la Dodd-Frank Act aprobada en 2010 a resultas de la grave crisis financiera - incrementó los incentivos para los denunciantes, a quienes se ofrecen importantes compensaciones económicas en caso de aportar información relevante sobre posibles fraudes en el sector financiero. ${ }^{8}$ Dichas retribuciones suponen un porcentaje entre el 10 y el 30\% de las multas de más de un millón de dólares que puedan acabar imponiéndose gracias a la información recibida.

Las reticencias que plantean estímulos de esta naturaleza son, sobre todo, de carácter cultural. Así, el riesgo de incentivar denuncias falsas o poco fundadas puede reducirse — como, de hecho, se hace en los Estados Unidos - condicionando el pago de la recompensa a la efectiva percepción por parte de las arcas públicas de las correspondientes multas o indemnizaciones. Sin embargo, en muchos países suscita recelos que el Estado retribuya a quien, después de todo, ha delatado a quienes eran sus jefes o superiores, una perspectiva que puede cambiar, no obstante, si en el pago no se advierte un premio, sino más bien una forma de reparación por los perjuicios que muchos denunciantes sufren, en especial, el ostracismo laboral definitivo en el que suelen caer en determinados sectores quienes osan denunciar a su propia empresa o a sus jefes.

c) Ofrecimiento de protección: a menudo el principal obstáculo para que un sujeto denuncie las actividades irregulares de las que tiene conocimiento es el temor a sufrir en carne propia o en la de seres queridos algún tipo de represalia por parte de la persona denunciada. ${ }^{9}$ En el caso de empleados que denuncian prácticas ilícitas en las que puede haber incurrido la empresa para la que trabajan o sus superiores, dicho temor suele asociarse con la posibilidad de ver frustradas sus legítimas expectativas de promoción profesional o se concreta en el riesgo de un posible despido laboral. También existe el temor a ser demandado por la propia empresa o administración denunciada en caso de que finalmente la denuncia no prospere o se considere infundada. ${ }^{10}$ Otros miedos pueden ser algo más difusos, pero sin duda comprensibles, como el temor a ser visto como un soplón por las personas con las que se coincide cotidianamente en el puesto de trabajo. Ante estas circunstancias un posible recurso para fomentar las denuncias puede consistir en otorgar protección jurídica al sujeto que esté dispuesto a informar: esta es una de las vías por las que claramente se ha optado en países como los Estados Unidos, donde impera un sistema de despido libre, en reformas como la que en 2002 supuso la Sarbanes-Oxley Act, dictada en su momento para dar respuesta a graves fraudes corporativos como los casos Enron y WorldCom.

En la Unión Europea, la Directiva 2019/1937 del Parlamento Europeo y del Consejo, relativa a la Protección de las Personas que informen sobre Infracciones del Derecho de la Unión, ha

FELDMAN y LOBEL (2010), p. 1168). Estos últimos autores aportan referencias adicionales de leyes que prevén tales incentivos.

${ }^{8}$ Véanse varios autores (QUIGLEY (2012), p. 257 ss. y 268 ss.; LEE (2011-12), pp. 303-339).

9 Sobre los temores de los denunciantes, OCDE (2012), p. 3. Ver asimismo varios autores (FELDMAN y LOEBEL (2010), passim; RAPP (2007), pp. 95 y 118 ss,). Este último muestra con ejemplos reales perjuicios que en la práctica han sufrido algunos denunciantes. Además, en p. 118, el último autor alude a estudios que señalan que un $33 \%$ de los denunciantes afirma que no volvería a hacerlo debido a las malas experiencias que su decisión le ha comportado. Ver igualmente GARCÍA-MORENO (2020), pp. 93-95.

${ }^{10}$ Sobre esta posibilidad, RAPP (2007), p. 125 ss. 
optado claramente por este modelo. Este texto obliga a los estados miembros a imponer a las empresas y administraciones de una cierta entidad (cincuenta trabajadores en el caso de las primeras) procedimientos de denuncia que garanticen a los denunciantes protección frente a cualquier tipo de represalia. Dicha protección debe dispensarse tanto a nivel laboral (nulidad de cualquier medida represora) como sancionatorio (imposición de castigos al responsable de las represalias), tanto si el trabajador ha denunciado internamente ante la propia empresa como externamente ante la administración. Además, se establece una inversión de la carga de la prueba en beneficio del denunciante cuando a su actuación le ha seguido en el tiempo algún tipo de perjuicio laboral. Todo ello sin perjuicio de las previsiones penales y procesales que puede tener cada Estado miembro para proteger a los denunciantes-testigos en aquellas situaciones (por fortuna, infrecuentes) en los que puede estar en riesgo su salud o integridad física. ${ }^{11}$

En esta misma línea, también resulta importante ofrecer algún tipo de respuesta jurídica a aquellos casos en los que el denunciante asume el riesgo de su propia imputación penal. Hay que tener presente que, en ocasiones, quien denuncia a su empresa o a sus superiores lo hace revelando información reservada, lo que le expone a ser denunciado por posibles delitos de descubrimiento de secretos. Para evitar que esto suceda puede ser conveniente reconocer a los denunciantes algún tipo de causa de justificación. En tal sentido, la Directiva Europea dispone en su art. 21.3, que "los denunciantes no incurrirán en responsabilidad respecto de la adquisición o el acceso a la información que es comunicada o revelada públicamente, siempre que dicha adquisición o acceso no constituya de por sí un delito", una cláusula bienintencionada pero ambigua, por cuanto en la frase final no se excluye que, en ciertos casos, pueda cometerse una infracción penal en caso de revelar información confidencial en el contexto de una denuncia. En tal sentido, las situaciones más arriesgadas para el alertador son aquellas en las que, no solo se informa de la concreta irregularidad cometida (una información que, en sí misma, no queda abarcada por ninguna expectativa legítima de reserva), sino que al denunciar se revela información confidencial de terceros carentes de responsabilidad en aquel hecho que se denuncia. ${ }^{12}$

d) Ofrecimiento de exención o atenuaciones sancionatorias: con cierta frecuencia es posible que el sujeto que está en condiciones de informar haya tenido algún tipo de intervención en el hecho delictivo que denuncia, de modo que no se decida a acudir a las autoridades por temor a acabar siendo él mismo procesado o sancionado. En aquellos casos en los que hayan intervenido en el hecho otros sujetos —especialmente cuando estos últimos hayan tenido un protagonismo mayor en la actuación delictiva - cabe plantearse la posibilidad de otorgar al denunciante algún tipo de rebaja punitiva por su colaboración con la justicia o, incluso, la plena exención cuando su aportación a la conducta ilícita no haya sido de primer orden y, en cambio, su información permita obtener importantes pruebas de hechos que revistan una especial gravedad.

Tradicionalmente en los sistemas procesales anglosajones, basados en el principio de oportunidad, las acusaciones han contado con amplias posibilidades de pactar con los delatores y ofrecerles la impunidad a cambio de su testimonio. Esto no resultaba por lo

\footnotetext{
${ }^{11}$ Para más detalles, RAGUÉS (2020), pp. 1-13.

12 Cuestión analizada en RAGUÉS (2015), pp. 1-34.
} 


\section{Polít. Crim. Vol. 16, No 31 (Julio 2021), Art. 1, pp. 1-29 [http://politcrim.com/wp-content/uploads/2021/04/Vol16N31A1.pdf]}

general posible en los sistemas continentales, basados en el principio de legalidad procesal y en los que, a lo sumo, pueden ofrecerse atenuaciones a los sujetos que colaboran con la justicia. Sin embargo, en tiempos recientes algunas voces empiezan a plantear la necesidad de que en estos últimos sistemas se prevea la exención total de pena, ${ }^{13}$ por lo menos para los colaboradores respecto de determinados delitos, en la línea de lo que ya se prevé en muchos sistemas jurídicos para el derecho de la competencia, donde rigen los llamados programas de clemencia o delación compensada, que permiten eximir de todo castigo al primer interviniente en un acuerdo anticompetitivo que confiesa a las autoridades.

Todos los medios expuestos tienen sus pros y sus contras y, en distinta medida, todos o algunos de ellos han sido previstos y empleados, según los países, en los últimos años. En los Estados Unidos, por ejemplo, se ha optado por un cóctel que abarca casi todos los incentivos: reforzar las recompensas económicas, imponer deberes de denuncia a sujetos que ejercen determinadas profesiones y otorgar protección jurídica y exenciones penales a los informantes. En la Europa continental, en cambio, se ha preferido un modelo de protección, pues existen todavía importantes recelos ante la figura del denunciante que desaconsejan que se le sobreestimule con recompensas de naturaleza económica y, en la mayoría de países, con el premio de la exención total de pena en casos de colaboración con la justicia. ${ }^{14} \mathrm{~A}$ continuación, procede pasar a analizar cuál es la situación en Chile.

\section{Situación del denunciante de irregularidades e ilícitos administrativos y delitos en Chile}

Para determinar cómo los distintos modelos de incentivo al whistleblower se concretan en la regulación chilena, será imprescindible distinguir en los apartados que siguen entre la situación de los empleados del sector privado y los funcionarios públicos. Además de exponer la regulación vigente en cada punto, se hará referencia asimismo a las iniciativas de modificación legal que se han presentado recientemente con el objeto de promover la actuación de los denunciantes.

\subsection{Deberes de denuncia}

El art. 175 del Código Procesal Penal establece en qué casos debe presentarse obligatoriamente denuncia en virtud de la comisión de un delito. Mientras a muy pocos particulares se les impone esta obligación, respecto de los funcionarios públicos se prevé un deber general de denunciar. En efecto, la referida norma dispone:

"Artículo 175.- Denuncia obligatoria. Estarán obligados a denunciar:

a) Los miembros de Carabineros de Chile, de la Policía de Investigaciones de Chile y de Gendarmería, todos los delitos que presenciaren o llegaren a su noticia. Los miembros de las Fuerzas Armadas estarán también obligados a denunciar todos los delitos de que tomaren conocimiento en el ejercicio de sus funciones;

\footnotetext{
${ }^{13}$ Por ejemplo, ORTIZ (2018), passim.

${ }^{14}$ Tales recelos pueden observarse por ejemplo en Alemania, con trabajos como HEFENDEHL (2009), pp. 617643.
} 
b) Los fiscales y los demás empleados públicos, los delitos de que tomaren conocimiento en el ejercicio de sus funciones $\mathrm{y}$, especialmente, en su caso, los que notaren en la conducta ministerial de sus subalternos;

c) Los jefes de puertos, aeropuertos, estaciones de trenes o buses o de otros medios de locomoción o de carga, los capitanes de naves o de aeronaves comerciales que naveguen en el mar territorial o en el espacio territorial, respectivamente, y los conductores de los trenes, buses u otros medios de transporte o carga, los delitos que se cometieren durante el viaje, en el recinto de una estación, puerto o aeropuerto o a bordo del buque o aeronave;

d) Los jefes de establecimientos hospitalarios o de clínicas particulares y, en general, los profesionales en medicina, odontología, química, farmacia y de otras ramas relacionadas con la conservación o el restablecimiento de la salud, y los que ejercieren prestaciones auxiliares de ellas, que notaren en una persona o en un cadáver señales de envenenamiento o de otro delito;

e) Los directores, inspectores y profesores de establecimientos educacionales de todo nivel, los delitos que afectaren a los alumnos o que hubieren tenido lugar en el establecimiento.

La denuncia realizada por alguno de los obligados en este artículo eximirá al resto, y

f) Los jefes de establecimientos de salud, públicos o privados, y los sostenedores y directores de establecimientos educacionales, públicos o privados, respecto de los delitos perpetrados contra los profesionales y funcionarios de dichos establecimientos al interior de sus dependencias o mientras éstos se encontraren en el ejercicio de sus funciones o en razón, con motivo u ocasión de ellas. La misma obligación tendrán los directores de los Servicios Locales de Educación respecto de estos delitos, cuando ocurran en los establecimientos educacionales que formen parte del territorio de su competencia."

Como se desprende de este enunciado, en relación con los particulares la obligación de denunciar se ve relevantemente acotada en virtud de la calidad de la persona obligada (en general, personas que tienen a su cargo labores de dirección y vigilancia en la prestación de un servicio específico), del sector de actividad en el que desempeña sus labores (ámbitos en que puede verificarse con relativa regularidad cierta naturaleza de delincuencia) y del tipo de ilícito que se encuentra vinculado a ese particular contexto. Se trata de los gatekeepers a los que se hacía referencia anteriormente.

Desde inicios de 2018 se encuentra en discusión una iniciativa legislativa para ampliar la imposición del deber de denunciar del art. 175 del Código Procesal Penal a las autoridades eclesiásticas de cualquier confesión religiosa respecto de cualquier delito cometido en contra de niños, niñas, adolescentes y personas que, por su condición física o mental, no puedan ejercitar sus derechos por sí mismos. ${ }^{15}$ Sin embargo, más allá de este caso concreto, lo cierto

\footnotetext{
15 Véase tramitación Boletín 11768-07, que "Modifica el Código Procesal Penal para imponer a las autoridades religiosas o eclesiásticas que indica, la obligación de denunciar hechos que revistieren caracteres de delito, contra menores de edad y personas impedidas de ejercer con autonomía sus derechos, y de que tomaren conocimiento en virtud de fus funciones", https://www.camara.cl/legislacion/ProyectosDeLey/tramitacion.aspx?prmID=12288\&prmBOLETIN=11768-
} 


\section{Polít. Crim. Vol. 16, № 31 (Julio 2021), Art. 1, pp. 1-29 [http://politcrim.com/wp-content/uploads/2021/04/Vol16N31A1.pdf]}

es que la imposición de un deber general de denuncia para particulares no se ha planteado en la discusión chilena, como es regla general en el derecho comparado. La misma situación legal se observa respecto de la denuncia de ilícitos administrativos. Esta circunstancia tiene, en todo caso, la consecuencia negativa para el denunciante de impedir la alegación, de entrada, de una causa de justificación a su favor en caso de incurrir en algún delito de revelación de información con ocasión de la denuncia.

Por el contrario, en el caso de los funcionarios públicos es claro que estos sí tienen una obligación general de presentar denuncia de los delitos que constaten en el ejercicio de sus atribuciones, como se evidencia claramente de la norma citada, especialmente de los literales a) y b). Además, dichos funcionarios se encuentran sometidos a la obligación de denunciar no solamente delitos, sino también cualquier otra irregularidad, especialmente si esta configura una infracción al principio de probidad administrativa. En efecto, en el año 2007 se aprobó la Ley 20.205 ("Protege al funcionario que denuncia irregularidades y faltas al principio de probidad"), que incorporó modificaciones al Estatuto Administrativo, al Estatuto Administrativo Municipal y a la Ley Orgánica Constitucional de Bases de la Administración del Estado (en adelante, LOCBGAE), con el objetivo de incorporar a la legislación chilena la obligación del funcionario público de denunciar irregularidades vinculadas a la infracción del principio de probidad, en un contexto en el que se habían destapado diversos casos de corrupción. ${ }^{16}$

Actualmente, el art. 61.k) del Estatuto Administrativo dispone, entre las obligaciones de cada funcionario público, la de "denunciar ante el Ministerio Público o ante la policía si no hubiese fiscalía en el lugar en que el funcionario presta servicios, con la debida prontitud, los crímenes o simples delitos y a la autoridad competente los hechos de carácter irregular, especialmente de aquéllos que contravienen el principio de probidad administrativa regulado por la ley $\mathrm{N}^{\circ} 18.575$ ”. Esta misma obligación existe respecto de funcionarios municipales. ${ }^{17}$

En junio de 2020, en el marco de la "Agenda antiabusos" del Gobierno de Chile ${ }^{18}$ ingresó a tramitación en la Cámara de Diputados un proyecto de Ley que tiene la pretensión de

07 [última visita: 28-09-2020]. Esta iniciativa parlamentaria se enmarca en un contexto de descubrimiento de una serie de graves abusos sexuales cometidos por sacerdotes de la Iglesia Católica en contra de menores de edad a lo largo de varios años, que permanecieron impunes, en gran parte, por la pasividad de las autoridades eclesiásticas pese a que habrían tenido conocimiento de los hechos. La moción aporta antecedentes de Derecho comparado, señalando que en México existiría la obligación de denunciar para este tipo de autoridades. Además, la política de la autoridad papal de terminar con los abusos por parte de la Iglesia Católica se habría expresado en modificaciones al Derecho canónico con el objeto de exigir una mayor diligencia por parte de obispos y otros jerarcas católicos respecto de este tipo de denuncias. A este respecto, y en particular sobre la relación de este eventual deber con el secreto de confesión, véase PIMSTEIN (2019), passim.

${ }^{16}$ Véase Historia de la Ley 20.205 en https://www.bcn.cl/historiadelaley/nc/historia-de-la-ley/5276/ [última visita: 05-06-2020].

${ }^{17}$ Conforme a la LOCBGAE, la probidad es un principio de la administración pública, que "consiste en observar una conducta funcionaria intachable y un desempeño honesto y leal de la función o cargo, con preeminencia del interés general sobre el particular" (art. 52). Teniendo el principio de probidad un tratamiento detallado en el Título III de la referida normativa, su art. 62 dispone casos en los que especialmente se constata una contravención al principio de probidad administrativa.

${ }^{18}$ En marzo de 2020 el Gobierno de Chile presentó a la ciudadanía la denominada "Agenda antiabusos", que tendría como objetivo la persecución más eficaz de los "delitos de cuello y corbata". En este sentido, se anunció 
establecer un estatuto de protección en favor del denunciante y que, por lo tanto, será comentado a propósito de distintos aspectos en el presente epígrafe (en adelante, Proyecto de Ley del Denunciante). ${ }^{19}$ Este proyecto establece una serie de medidas de protección a favor de personas que denuncien infracciones disciplinarias, faltas administrativas, hechos de corrupción o que afectaren o pudieran afectar recursos públicos, en los que tuviere participación algún funcionario u organismo de la Administración del Estado. En lo que al deber de presentar denuncia por parte de funcionarios públicos respecta, se establece que la referida obligación recaiga no solamente sobre personas sujetas al estatuto administrativo, sino que también sobre aquellos contratados a honorarios (transitoriamente) o sujetos a contratos de trabajo. ${ }^{20}$

\subsection{Recompensas económicas}

En Chile no están previstos, hoy por hoy, incentivos económicos para motivar a eventuales denunciantes de delitos o irregularidades, pese a las opiniones de alguna doctrina que, desde hace algún tiempo, recomienda tales estímulos como el mecanismo (supuestamente) más eficaz para promover las denuncias. ${ }^{21}$ Atendiendo a tales recomendaciones, en noviembre de 2019 un grupo de parlamentarios del oficialismo presentó un proyecto de Ley con el objeto de incorporar un incentivo económico a favor del denunciante en casos de delitos de colusión (DL 211, art. 62) y de corrupción (que son identificados por los parlamentarios como aquellos que se encuentran en la Ley 20.393, de responsabilidad penal de personas jurídicas). Según la moción de inicio, "en Chile no existen incentivos asociados a la denuncia de corrupción. Ello quiere decir que si algún trabajador de [sic] entera de una mala práctica en su empresa, nada le asegura que la autoridad administrativa conservará su anonimato, o que la empresa

la presentación de proyectos de ley con modificaciones en las herramientas de combate respecto de cuatro tipos de delitos: colusión, uso de información privilegiada, corrupción y delitos electorales. Sin embargo, es pertinente tener en consideración que el propósito de regular medidas eficaces para prevenir y sancionar la corrupción ha venido siendo una constante preocupación de distintos gobiernos. En este sentido, uno de los antecedentes más relevantes es: CONSEJO ASESOR PRESIDENCIAL CONTRA LOS CONFLICTOS DE INTERÉS, EL TRÁFICO DE INFLUENCIA Y LA CORRUPCIÓN (2015), passim.

19 Véase tramitación Boletín 13565-07, que "Establece un nuevo Estatuto de Protección en favor del Denunciante",

https://www.camara.cl/legislacion/ProyectosDeLey/tramitacion.aspx?prmID=14105\&prmBOLETIN=1356507 [última visita: 28-09-2020].

${ }^{20}$ De esta manera, esta regulación pondría término a la incertidumbre acerca de si las normas que vinculan a "funcionarios públicos" son aplicables a personas que desempeñan sus labores en la Administración del Estado, pero que se encuentran sujetos a normativas distintas al Estatuto Administrativo. De hecho, ya en octubre de 2018 había sido presentado un proyecto de Ley con el objeto de extender la obligación de presentar denuncia al personal de las Fuerzas Armadas. A este respecto, véase tramitación en Boletín 12211-02 (refundido con 12948-02), proyecto de Ley que "Modifica la ley $N^{\circ} 20.205$, que Protege al funcionario que denuncia irregularidades y faltas al principio de probidad, para extender su aplicación al personal de las Fuerzas Armadas, en las condiciones que señala", y, especialmente, HORZELLA (2019), passim. Todo lo anterior, en https://www.camara.cl/legislacion/ProyectosDeLey/tramitacion. aspx?prmID=12733\&prmBOLETIN=1221102 [última visita: 28-09-2020].

${ }^{21}$ Un trabajo seminal a este respecto es AUBERT et al. (2006), pp. 1241-1266. Aunque su ámbito de estudio se dedica exclusivamente a los carteles como infracciones a la libre competencia en los mercados, algunas de sus conclusiones son trasladables a otros ámbitos. En el presente contexto, es pertinente considerar que los resultados de tal estudio arrojan que la recompensa a individuos es una herramienta para desbaratar carteles incluso más eficaz que los programas de clemencia o delación compensada. En Chile se muestra favorable a la recompensa como mecanismo de incentivo, AGÜERO (2015), passim. 


\section{Polít. Crim. Vol. 16, № 31 (Julio 2021), Art. 1, pp. 1-29 [http://politcrim.com/wp-content/uploads/2021/04/Vol16N31A1.pdf]}

en cuestión no podrá tomar represalias en contra de dicho trabajador". ${ }^{22}$ Con el objeto de incentivar la denuncia y animar a los potenciales alertadores a vencer sus reticencias, pretende ofrecerse una recompensa para el denunciante de hasta el $20 \%$ de la multa obtenida por causa de los delitos perseguidos. El Gobierno de Chile, por su parte, ha anunciado que su Agenda Antiabusos sólo contempla la recompensa al denunciante en casos de uso de información privilegiada. ${ }^{23}$ Esto se ha evidenciado en los proyectos de ley presentados en el marco de esta estrategia.

\subsection{Protección al denunciante dispensada por el ordenamiento jurídico}

\subsubsection{Protección de identidad}

Una manera de vencer los temores de un eventual denunciante puede ser garantizar la protección de su identidad. Tal garantía, sin embargo, no se brinda en términos absolutos en la legislación chilena: así, en el ámbito de la denuncia de delitos, el Código Procesal Penal exige que el denunciante señale su identidad (art. 174) en el marco de un proceso que será público, por regla general (art. 44). Asimismo, la normativa es expresa en señalar que el denunciante no es un interviniente del proceso y no contrae más responsabilidad que la que se encuentra aparejada a los delitos que puede estar cometiendo a través o con ocasión de su denuncia (art. 178). Durante el desarrollo del proceso, en caso de que el denunciante sea citado a declarar como testigo, podrá ser sujeto a las medidas de protección general, de naturaleza discrecional del Tribunal (por ejemplo, las medidas de protección de los arts. 307 y 308).

Este marco regulatorio, que exige, por regla general, el conocimiento de la identidad del denunciante, ha sido reconocido por la institucionalidad política como un obstáculo a la práctica de la denuncia, por lo que la Subsecretaría de Prevención del Delito del Ministerio del Interior ha puesto a disposición de la ciudadanía un programa denominado "Denuncia Seguro", cuyo objeto es alentar a las personas que han presenciado o han sido víctimas de un delito a llamar de manera anónima por vía telefónica a funcionarios del Ministerio, quienes, con posterioridad, presentan una denuncia formal dando cumplimiento a los requisitos legales. ${ }^{24-}$

\footnotetext{
22 Véase tramitación en Boletín 13111-03, proyecto de Ley que "Modifica diversos cuerpos legales para establecer un incentivo económico a favor del denunciante en los delitos de colusión y aquellos que acarrean responsabilidad penal de las personas jurídicas”, en https://www.camara.cl/legislacion/ProyectosDeLey/tramitacion.aspx?prmID=13656\&prmBOLETIN=1311103 [última visita: 28-09-2020].

${ }^{23}$ Véase "Piñera presenta agenda antiabusos que incluye recompensa a informantes", El Mercurio Inversiones, viernes 13 de marzo de 2020, https://www.elmercurio.com/Inversiones/Noticias/Analisis/2020/03/13/Presidente-Pinera-anuncia-agendaantiabusos-que-incluye-recompensa-a-informantes.aspx. [última visita: 25-06-2020]; y "Gobierno descarta recompensa a denunciante anónimo en proyecto que fortalece a la FNE", La Segunda, martes 5 de mayo de 2020, en: http://cache-elastic.emol.com/2020/05/05/C/373PO2MD/all [última visita: 25-06-2020].

${ }^{24}$ Más antecedentes sobre el programa "Denuncia Seguro" en http://www.denunciaseguro.cl/ [última visita: 2905-2020].

Conforme al entendimiento actual de la Corte Suprema, la denuncia anónima no constituiría ni siquiera un indicio a efectos del control de identidad del art. 85 del Código Procesal Penal. Al respecto, véase DUCE (2020), passim. En esta columna, el autor se refiere a recursos de nulidad acogidos por la Corte Suprema durante mayo
} 
En relación con la denuncia de ilícitos administrativos, lo primero que se constata es la inexistencia de una normativa general que regule medidas de protección para el denunciante en los diversos ámbitos de la administración: mercado financiero, medio ambiente, salud, libre competencia, etc., quedando relegado su tratamiento a cada una de las normativas sectoriales, lo que desde ya genera un espacio de incertidumbre. Además, de la revisión de las normativas legales relativas a cada sector es posible constatar que en ellas se exige expresamente la identificación del denunciante, como ocurre, por ejemplo, en el sector medioambiental (Ley 20.417, art. 47) y el Código de Aguas (Decreto con Fuerza de Ley 1122, art. 172 bis); o bien la exigencia de identificación se sigue de su contexto, como sucede, a modo de referencia, con el Código Sanitario (arts. 161 y 164 del Decreto con Fuerza de Ley 725), el mercado financiero (Ley 21.000, art. 25) ${ }^{25}$ y la libre competencia, contenido en el Decreto Ley 211 (en adelante, DL 211), art. 41 similar al de la Ley 21.000 de mercado financiero). Todo ello en un marco general en el que operan como normas supletorias la Ley 19.880, que establece las bases de los procedimientos administrativos, que tiene como uno de sus principios el de transparencia y publicidad (arts. $4^{\circ}$ y 16 ) y la Ley 20.285 sobre acceso a la información pública, entre otras.

El Proyecto de Ley del Denunciante contempla modificar el Código Procesal Penal en el sentido de que sea posible presentar una denuncia de delitos sujeta a la reserva de identidad de la persona que acude al Ministerio Público. La reserva de identidad también se garantizaría en caso de denuncias de infracciones disciplinarias o faltas administrativas, las que se presentarían en un nuevo canal de denuncias que administraría la Contraloría General de la República (más adelante volveremos sobre la instauración de este canal receptor de denuncias). Conforme al Mensaje que dio inicio a la tramitación del referido proyecto, "La reserva de la identidad del denunciante constituye, en los hechos, la medida más eficaz para prevenir la realización de actos de represalia u hostigamiento en contra de éste o de sus cercanos, como consecuencia de la realización de una denuncia, circunstancia que la convierte, además, en uno de los estímulos más relevantes para su realización, en la medida que asegura al denunciante un ambiente protegido y seguro para la denuncia". ${ }^{26}$

Otro proyecto de Ley de la referida "Agenda antiabusos" del Gobierno (apartado 2.1) recae en el ámbito de la libre competencia, y también contempla la protección del denunciante a través de la reserva de su identidad. ${ }^{27}$ En efecto, la iniciativa legal del gobierno, presentada

de 2020, varios de los cuales se basaron en controles de identidad realizados por la policía tras una denuncia anónima.

${ }^{25} \mathrm{Si}$ bien es cierto que el referido artículo no establece expresamente los requisitos de la denuncia, se colige que es precisa una identificación por parte del denunciante en virtud de la facultad del fiscal de la Comisión para el Mercado Financiero de solicitar mayores antecedentes y la prestación de una declaración. Además, en aquel caso en que es posible realizar una denuncia anónima, el legislador la ha regulado expresamente, como en el caso de presuntas infracciones cometidas por algún miembro del Comité de Autorregulación Financiera, según dispone el art. 78 de la Ley 21.000.

${ }^{26}$ Boletín 13565-07, Mensaje del Presidente de la República, p. 14. Otra modificación al Código Procesal Penal consistiría en la inclusión de la facultad del Ministerio Público de poder disponer otras medidas de protección a favor del denunciante sin perjuicio de que este carezca de la calidad de interviniente del proceso penal.

${ }^{27}$ Es preciso tener en consideración que, conforme al art. 39 letra a) del DL 211, el Fiscal Nacional Económico, con conocimiento del Presidente del Tribunal de Defensa de la Libre Competencia, puede disponer que las investigaciones tengan el carácter de reservadas. Además, puede disponer de oficio que ciertas piezas del 


\section{Polít. Crim. Vol. 16, № 31 (Julio 2021), Art. 1, pp. 1-29 [http://politcrim.com/wp-content/uploads/2021/04/Vol16N31A1.pdf]}

en marzo de 2020, pretende fortalecer la persecución y sanción de carteles (acuerdos duros entre competidores). ${ }^{28}$ Uno de los propósitos del proyecto de ley guarda relación con la inclusión del denunciante anónimo. ${ }^{29}$ Los fundamentos de esta modificación legal son idénticos a los señalados a propósito del Proyecto de Ley del Denunciante: generar incentivos a las personas para que estas venzan sus temores a sufrir represalias u hostigamiento y decidan colaborar con la autoridad. ${ }^{30}$

Para evitar el abuso de este mecanismo de protección de identidad, ambos proyectos de ley sancionan como delito la presentación de denuncia falsa, pero lo hacen de manera distinta, lo que no deja de ser curioso tratándose en ambos casos de iniciativas legales del Gobierno presentadas con solo meses de desfase. En efecto, mientras el Proyecto de Ley del Denunciante modifica el art. 211 del Código Penal, renovando la figura de la denuncia calumniosa de manera de abarcar no solo la imputación de delitos, sino también de infracciones administrativas o disciplinarias, sancionándolo con una pena de presidio menor en su grado mínimo a medio (61 días a 3 años de privación de libertad) y multa de una a veinte unidades tributarias mensuales, dependiendo de la gravedad de los hechos denunciados falsamente; ${ }^{31}$ el proyecto de Ley en el ámbito de libre competencia pretende

expediente, cumplidas las circunstancias normativas, tengan el carácter de reservadas (lo que también es posible en investigaciones en otros ámbitos de la administración). Con el uso de estas facultades, la Fiscalía Nacional Económica ha podido en diversas ocasiones proteger la identidad del denunciante. Sin embargo, es preciso considerar que, más allá de satisfacerse los estándares normativos del DL 211 y de las demás normas de regulación administrativa que la alcanzan, estamos frente a un proceso que, eventualmente, llega a ventilarse en un juicio de carácter público ante el Tribunal de Defensa de la Libre Competencia. Es cierto que la reserva podría mantenerse conforme lo dispone la respectiva normativa, pero tal circunstancia estará sometida permanentemente a las tensiones de un procedimiento jurisdiccional y contencioso con todas las garantías que merece la defensa.

${ }^{28}$ Véase tramitación Boletín 13312-03, proyecto de Ley que "Fortalece la investigación y persecución de carteles y aumenta su pena en caso que indica”, en https://www.camara.cl/legislacion/ProyectosDeLey/tramitacion.aspx?prmID=13852\&prmBOLETIN=1331203 [última visita: 28-09-2020].

${ }^{29}$ Entre otros objetivos destacables del proyecto de Ley se cuentan la entrega de nuevas herramientas a la Fiscalía Nacional Económica para fortalecer sus investigaciones y el aumento de la pena asignada al delito de colusión. La necesidad y corrección de estos objetivos son objeto de polémica, como dan cuenta varios autores (PELLEGRINI y RAMOS (2020), passim; BARAHONA y LEITON (2020), passim).

${ }^{30}$ En efecto, este proyecto de Ley señala que muchas veces, personas que no han participado activamente en una conducta colusoria, pero tienen conocimiento de su existencia, se abstendrían de reportar el ilícito "por temor a eventuales represalias de la empresa o grupo empresarial del que forman parte, o de otros ejecutivos o compañías del mismo mercado o industria, las que pueden significar serios perjuicios en el ámbito laboral y social, especialmente en rubros pequeños o especializados. En casos graves, incluso, las represalias pueden tomar la forma de hostigamientos, apremios o amenazas a la vida o integridad física del denunciante", Boletín 13312-03, Mensaje del Presidente de la República, pp. 14-15. En este específico ámbito de libre competencia, el Ejecutivo habría seguido los lineamientos de la OCDE, expresados en el instrumento Recommendation of the Council concerning Effective Action against Hard Core Cartels, 2019.

${ }^{31}$ El artículo 211 del Código Penal que se propone en el Proyecto de Ley del Denunciante es el siguiente: "Artículo 211. El que maliciosamente presentare una denuncia por la cual se imputare falsamente a otra persona un hecho determinado constitutivo de delito, infracción administrativa o infracción disciplinaria será sancionado con:

1. Con la pena de presidio menor en su grado medio y multa de once a veinte unidades tributarias mensuales si el hecho imputado fuere constitutivo de crimen;

2. Con la pena de presidio menor en sus grados mínimo a medio y multa de seis a diez unidades tributarias mensuales si el hecho imputado fuere constitutivo de simple delito o de infracción administrativa; 
crear un nuevo tipo penal que, incorporado en el DL 211, sanciona a quien presente una denuncia "a sabiendas, en antecedentes falsos o fraudulentos, con el propósito de perjudicar a otros agentes económicos" con la pena de presidio menor en su grado mínimo a medio (61 días a 3 años de privación de libertad), sin contemplar la pena de multa.

En cuanto a los funcionarios públicos, la regulación ya comentada, que establece el deber de denunciar delitos e infracciones a la probidad, tiene también en cuenta la preocupación del empleado público de que se conozca su identidad. Es por ello que el art. $90 \mathrm{~B}$ del Estatuto Administrativo (y 80 B del Estatuto Administrativo Municipal), al momento de señalar los requisitos con que debe contar la denuncia, señala que podrá solicitarse el secreto de la identidad del denunciante o los datos que permitan determinarla, quedando así prohibida la divulgación de esta información. Como contrapartida, se prevé la circunstancia de que se presenten denuncias falsas por parte de funcionarios públicos. Esta circunstancia se considera - paradójicamente - una contravención al principio de probidad administrativa, ${ }^{32}$ pudiendo sancionarse con la destitución (art. 125 del Estatuto Administrativo y art. 123 del Estatuto Administrativo Municipal). Lo anterior, lógicamente, sin perjuicio de la comisión de algún delito, como el de denuncia calumniosa. Como se dijo previamente, el Proyecto de Ley del Denunciante mantiene y fortalece la reserva de la identidad si la denuncia es realizada utilizando el canal dispuesto por la Contraloría General de la República.

\subsubsection{Protección laboral}

Dada la actual inexistencia de una protección absoluta de la identidad del denunciante particular y a que una de las mayores preocupaciones del trabajador de una empresa en la que se cometen delitos o irregularidades administrativas al momento de denunciar es ser objeto de represalias por parte de su empleador, superiores jerárquicos o pares, el Código del Trabajo regula ciertos mecanismos de auxilio para estos casos.

Además de la prohibición y sanción del acoso laboral, cuyos términos generales abarca represalias como las mencionadas, ${ }^{33}$ una norma de aplicación más específica en el ámbito que comentamos es el art. 485 del Código del Trabajo, referido al procedimiento de tutela laboral. Este procedimiento, que tiene por objeto proteger los derechos fundamentales del trabajador que pueden ser vulnerados con ocasión de la ejecución de normas laborales, resulta

3. Con la pena de presidio menor en su grado mínimo y multa de una a cinco unidades tributarias mensuales si el hecho imputado fuere constitutivo de falta o fuere de aquellos que diere lugar a una infracción disciplinaria. Para los efectos del inciso anterior, se entenderá también que denuncia el que presenta querella o formula acusación particular en un proceso penal."

${ }^{32}$ LOCBGAE, art. 62: "Contravienen especialmente el principio de la probidad administrativa, las siguientes conductas:

(...)

9. Efectuar denuncias de irregularidades o de faltas al principio de probidad de las que haya afirmado tener conocimiento, sin fundamento y respecto de las cuales se constatare su falsedad o el ánimo deliberado de perjudicar al denunciado."

${ }^{33}$ El inciso segundo del art. $2{ }^{\circ}$ del Código del Trabajo dispone en su segunda parte: "Asimismo, es contrario a la dignidad de la persona el acoso laboral, entendiéndose por tal toda conducta que constituya agresión u hostigamiento reiterados, ejercida por el empleador o por uno o más trabajadores, en contra de otro u otros trabajadores, por cualquier medio, y que tenga como resultado para el o los afectados su menoscabo, maltrato o humillación, o bien que amenace o perjudique su situación laboral o sus oportunidades en el empleo." 


\section{Polít. Crim. Vol. 16, No 31 (Julio 2021), Art. 1, pp. 1-29 [http://politcrim.com/wp-content/uploads/2021/04/Vol16N31A1.pdf]}

de aplicación en casos en los que el ejercicio de las facultades legales por parte del empleador limitan el ejercicio de los derechos y garantías constitucionales del trabajador, sin justificación o en forma desproporcionada o arbitraria. El inciso tercero de la referida norma expresa en su segunda parte que "[e]n igual sentido se entenderán las represalias ejercidas en contra de trabajadores por el ejercicio de acciones judiciales, por su participación en ellas como testigo o haber sido ofrecidos en tal calidad, o bien como consecuencia de la labor fiscalizadora de la Dirección del Trabajo". Este procedimiento tiene por objeto, además del cese inmediato de la acción vulneradora de derechos del trabajador, la imposición de medidas de reparación a cargo del empleador y la aplicación de multas a su respecto.

En este sentido, la Dirección del Trabajo ha señalado que:

"Del precepto legal fluye, que el legislador protegió a través de la acción de tutela, el derecho a no ser objeto de represalias en el ámbito laboral por el ejercicio de acciones administrativas o judiciales.

El derecho de indemnidad corresponde a la garantía del trabajador a no ser objeto de represalias por parte del empleador en el ejercicio de sus derechos laborales cualquiera sea su naturaleza, esto es, fundamentales específicos, legales o contractuales, como consecuencia de las actuaciones de organismos públicos en la materia, tanto judiciales como administrativos". ${ }^{34}$

Como ha señalado la Corte Suprema, este estatuto, conocido como de "indemnidad laboral", ha sido deducido de instrumentos internacionales y, por ello, aun no estando expresamente regulado en la Constitución Política de la República como un derecho fundamental, se protege como expresión de otros derechos fundamentales. En sus propios términos:

“(...) Es este contexto el que explica la aplicación del artículo 493 del Código del Trabajo a lo que la doctrina laboral denomina garantía de la indemnidad, y que, el texto del ramo, define como las represalias ejercidas en contra de los trabajadores, en razón o como consecuencia de la labor fiscalizadora de la Dirección del Trabajo o por el ejercicio de acciones judiciales, puesto que si bien no se encuentra prevista expresamente por el texto constitucional, igualmente emana de un derecho fundamental, cual es la tutela judicial efectiva, prevista en el artículo 25 de la Convención Americana de Derechos Humanos, y reconocida explícitamente en el artículo 5 del Convenio $\mathrm{N}^{\circ} 158$ de la Organización Internacional del Trabajo sobre Terminación del contrato de trabajo, y que refuerza lo que ordena el artículo 2 del Código del Trabajo, cuando señala que "corresponde al Estado amparar al trabajador en su derecho a elegir libremente su trabajo y velar por el cumplimiento de las normas que regula la prestación de los servicios", por lo que su vulneración constituye, también, una forma o modalidad de quebrantar los derechos fundamentales (...)." 35

Un aspecto interesante del estatuto de tutela laboral del cual la indemnidad forma parte, guarda relación con la carga de la prueba, toda vez que conforme al art. 493 del Código del Trabajo, si los antecedentes aportados por el denunciante constituyen indicio suficiente de

34 Véase Dirección del Trabajo, Ordinario $\mathrm{N}^{\circ} 2471$, de 6 de junio de 2017, en https://www.dt.gob.cl/legislacion/1624/w3-article-112155.html [última visita: 04-05-2020].

${ }^{35}$ Corte Suprema, Rol N ${ }^{\circ} 1.806-2015$, de 8 de marzo de 2016, c. $4^{\circ}$. 
que se produjo la vulneración de derechos acusada, es de carga del denunciado explicar los fundamentos de las medidas adoptadas y de su proporcionalidad. ${ }^{36}$

En cuanto a los funcionarios públicos, es pertinente considerar que la obligación de presentar denuncia de delitos e infracciones a la probidad administrativa a la que se ha hecho referencia anteriormente, es reforzada por especiales medidas de protección del denunciante, que tienen por objeto garantizar su permanencia y estabilidad laboral. ${ }^{37}$ En tal sentido, el art. $90 \mathrm{~A}$ del Estatuto Administrativo (norma que replica el art. 88 del Estatuto Administrativo Municipal) establece que los funcionarios públicos que presentaren denuncia:

“a) No podrán ser objeto de las medidas disciplinarias de suspensión del empleo o de destitución, desde la fecha en que la autoridad reciba la denuncia y hasta la fecha en que se resuelva en definitiva no tenerla por presentada o, en su caso, hasta noventa días después de haber terminado la investigación sumaria o sumario, incoados a partir de la citada denuncia.

b) No ser trasladados de localidad o de la función que desempeñaren, sin su autorización por escrito, durante el lapso a que se refiere la letra precedente.

c) No ser objeto de precalificación anual, si el denunciado fuese su superior jerárquico, durante el mismo lapso a que se refieren las letras anteriores, salvo que expresamente la solicitare el denunciante. Si no lo hiciere, regirá su última calificación para todos los efectos legales."

Estas medidas de protección han demostrado no ser totalmente eficaces. ${ }^{38}$ Por ello, el Proyecto de Ley del Denunciante propone ampliar la cobertura en diversos aspectos. Entre otros, es posible mencionar las siguientes: las personas que merecen protección (se pretende proteger a todos los funcionarios públicos y no sólo a aquellos sujetos al Estatuto Administrativo); el tiempo por el que se les concede indemnidad laboral (no se sujeta a un

${ }^{36}$ Una norma aún más específica en cuanto a su ámbito de aplicación se encuentra en el art. 290, letra c) del
Código del Trabajo, que contempla como práctica antisindical, la aplicación de sanciones de multa o expulsión
a un afiliado por no haber acatado una decisión ilegal o "por haber presentado cargos o dado testimonio en
juicio". Este es un caso concreto, aunque en un ámbito muy acotado, en el que se sanciona una práctica de
represalia en contra de un trabajador que ha denunciado una práctica ilegal.
${ }^{37}$ La protección que se comenta en este apartado es aquella que se encuentra regulada en normas del ámbito
administrativo. Por tanto, no se considera la discusión acerca de la aplicabilidad del Código del Trabajo, y
específicamente del procedimiento de tutela laboral respecto de empleados públicos, materia en que la Corte
Suprema y el Tribunal Constitucional han sostenido diversos y cambiantes criterios, como se sintetiza en
VERGARA (2020), passim.
38 Una de las razones es que el periodo de protección laboral (hasta 90 días después de terminado el sumario
administrativo) sería muy restringido, como señala AGÜERO (2015), pp. 5-6. El Proyecto de Ley del
Denunciante también se hace cargo de las carencias de la actual legislación, véase Boletín 13565-07, Mensaje
del Presidente de la República, pp. 15-20. En diciembre de 2019 se había presentado un proyecto de Ley por
un grupo de parlamentarios que tenía por objeto ampliar los mecanismos de protección para los funcionarios
públicos, véase tramitación Boletín $13115-06$, que "Modifica la ley No 18.834 , sobre Estatuto Administrativo,
para promover la denuncia, por parte de los funcionarios públicos, de los delitos y otros hechos irregulares de
los tengan conocimiento", https://www.camara.cl/legislacion/ProyectosDeLey/tramitacion.aspx?prmID=13658\&prmBOLETIN=1311506 [última visita: 28-09-2020], el que por su naturaleza más acotada, se decidió refundir con el Proyecto de Ley del Denunciante. 


\section{Polít. Crim. Vol. 16, No 31 (Julio 2021), Art. 1, pp. 1-29 [http://politcrim.com/wp-content/uploads/2021/04/Vol16N31A1.pdf]}

plazo fijo como lo hace la regulación vigente, sino que se deja a discreción de la Contraloría General de la República); y las medidas de protección (no solamente se amplían las medidas preventivas, considerando actos de represalia u hostigamiento diversos a los más severos que ya contempla la normativa actual, sino que también se establece un mecanismo de protección ex post, regulándose la declaración de ilegalidad de los actos del servicio público realizados como expresión de represalias).

2.3.3. Protección frente a responsabilidad penal: conductas típicamente relevantes vinculadas a la denuncia

Como se ha expuesto anteriormente (apartado 1), otro punto de interés en materia de whistleblowing es la protección jurídica que merece un denunciante que deba defenderse de una imputación penal que pueda formularse en su contra en virtud de su denuncia. Como ya se ha expuesto, esto puede suceder si, cuando se revela información a la autoridad, se ven afectados bienes jurídicos de las personas denunciadas que también merecen protección penal, como es el caso de la vida privada, intimidad y honor, entre otros ${ }^{39}$ En la regulación chilena, sin embargo, no existe una norma que expresamente exima de responsabilidad penal al denunciante que, en virtud de su denuncia, pueda satisfacer las exigencias típicas de un delito. Esto genera que la determinación se deje exclusivamente en manos del tribunal respectivo, que deberá realizar una valoración casuística, que poco ayuda a generar certeza jurídica a quien tenga información sobre un delito o irregularidad. Veamos algunos ejemplos: ${ }^{40}$

\section{a) Delito contra la vida privada e intimidad, art. 161-A del Código Penal}

Conforme al art. 161-A del Código Penal se sanciona al que "en recintos particulares o lugares que no sean de libre acceso al público, sin autorización del afectado y por cualquier medio, capte, intercepte, grabe o reproduzca conversaciones o comunicaciones de carácter privado; sustraiga, fotografíe, fotocopie o reproduzca documentos o instrumentos de carácter

\footnotetext{
${ }^{39}$ En RAGUÉS (2013), pp. 200-232 se realiza un detallado análisis de las conductas penalmente relevantes en que puede incurrir un denunciante y la manera en que dichas actuaciones pueden ser procesadas por el sistema penal español.

${ }^{40}$ Como se ha señalado anteriormente (apartado 1), en el Derecho comparado una de las grandes preocupaciones de los denunciantes surge del delito de violación de secretos. Sin embargo, en Chile la violación de secretos por parte de particulares es un delito que no ha sido objeto de actualización, relegándose al art. 284 del Código Penal, que refiere vagamente a "secretos de fábrica", por lo que no se comprenderían secretos comerciales o empresariales, ni otras informaciones reservadas o íntimas que pudieran estar en poder del empresario. Esta realidad pretende modificarse por el proyecto de Ley de delitos económicos ingresado a tramitación en enero de 2020, que en el marco de una regulación global sobre este tipo de delitos, fortalece también la protección de los secretos empresariales: al respecto, véase tramitación en Boletín 13205-07, proyecto de Ley que "Sistematiza los delitos económicos y atentados contra el medio ambiente, modifica diversos cuerpos legales que tipifican delitos contra el orden socioeconómico, y adecua las penas aplicables a todos ellos", en https://www.camara.cl/legislacion/ProyectosDeLey/tramitacion.aspx?prmID=13749\&prmBOLETIN=1320507 [última visita: 28-09-2020].

Mayor robustez tiene el tratamiento de la violación de secretos por parte de funcionarios públicos en los arts. 246 y 247 del Código Penal. Este último precepto también comprende a ciertos particulares que, por su profesión, tengan acceso a información que les ha sido confiada de manera secreta. Las normas que regulan el funcionamiento de instituciones públicas suelen remitirse a estas normas a efectos de la sanción penal de la infracción del deber de secreto.
} 
privado; o capte, grabe, filme o fotografíe imágenes o hechos de carácter privado que se produzcan, realicen, ocurran o existan en recintos particulares o lugares que no sean de libre acceso al público". También se sanciona a quienes difundan esa información privada. El último inciso dispone que esta norma no es aplicable a quienes se encuentran facultados legal o judicialmente para realizar algún tipo de intervención como la expresada por el referido precepto.

Los supuestos que resultan problemáticos son aquellos en los que un particular, con el objeto de recabar información para realizar una denuncia sobre algún delito o conducta irregular, incurre en alguno de los comportamientos abarcados por la norma. Esto se ha discutido en los tribunales a propósito de la labor de los medios de prensa. Como ejemplo cabe citar el caso de unos periodistas que, haciéndose pasar por pacientes, grabaron subrepticiamente a una reconocida médica emitiendo licencias falsas y luego ventilaron públicamente tal irregularidad. Nótese que se trata del caso más extremo de denuncia, pues no se siguió un camino formal ante ninguna autoridad pública, sino que la información fue revelada directamente por la televisión. El Juzgado del Crimen condenó a los periodistas por el delito del art. 161-A del Código Penal y la Corte de Apelaciones de San Miguel confirmó la condena. Sin embargo, la Corte Suprema anuló el fallo de segunda instancia, absolviendo a los acusados. El mecanismo escogido fue eludir la tipicidad del art. 161-A, señalando que la revelación de una irregularidad - no necesariamente un delito - constituye información de interés público:

"En el caso en análisis si bien no se ha demostrado la comisión de un ilícito por los presuntos perjudicados, lo cierto es que su conducta importa al menos una transgresión a la ética por parte de profesionales de la salud que otorgaban licencias médicas falsas en desmedro de los demás cotizantes de los sistemas de salud, cuestión que reviste un interés público con mérito suficiente para ser socializada lo que permitirá en último término, el fin de una situación reprobable e inconveniente.

Como advierte el recurso no ha podido estimarse que la conversación de los periodistas con la profesional sea de carácter privado, pues se refiere a hechos que revelan irregularidades de la praxis médica verificables para ante la opinión pública". ${ }^{41}$

Sin perjuicio de esta decisión, señalada a modo de ejemplo, la disparidad de criterio entre los tribunales, la inexistencia del principio de precedente en el ordenamiento jurídico chileno y la permanente rotación en la conformación de los tribunales no permite a un eventual denunciante confiar en que el mismo criterio le será aplicado en casos futuros.

\section{b) Delitos contra el honor}

Los delitos contra el honor que regula el Código Penal son la injuria (art. 416 del Código Penal) y la calumnia (art. 412, con su expresión específica de denuncia calumniosa en el art.

\footnotetext{
${ }^{41}$ Corte Suprema, Rol N ${ }^{\circ}$ 8.393-2012, de 21 de agosto de 2013, c. $4^{\circ}$. La sentencia también argumenta que la grabación misma no vulneraría la intimidad, pues quien graba es el mismo interlocutor en la conversación. Además, se alude a la Ley 19.733, de Prensa, para reforzar el interés público del mensaje difundido. Sin perjuicio de lo anterior, el razonamiento de la Corte Suprema se dirige a negar ya la misma tipicidad de la conducta, sin necesidad de alegar la configuración de alguna posible causa de justificación.
} 


\section{Polít. Crim. Vol. 16, № 31 (Julio 2021), Art. 1, pp. 1-29 [http://politcrim.com/wp-content/uploads/2021/04/Vol16N31A1.pdf]}

211). Aunque con diferencias típicas relevantes entre estas figuras, no es extraño pensar que cuando una persona denuncia una irregularidad que cree haber constatado en la organización en la que trabaja, pueda vulnerar el honor del denunciado, sobre todo en circunstancias en las que la injuria no requiere siquiera de la falsedad de la imputación. ${ }^{42}$

En un caso similar al señalado en el apartado anterior, que llegó al conocimiento de la Corte Suprema por medio de un recurso de protección interpuesto por un acusado al que un medio de comunicación habría grabado realizando solicitaciones sexuales a una mujer en un restaurante, el máximo Tribunal señaló que, tratándose de un hecho de relevancia pública, prevalecía la libertad de información al honor, por lo que la lesión de este último se encontraría justificada en la causa de interés público del asunto. ${ }^{43}$ La justificación en este supuesto recaía en el ejercicio de un derecho legal del cual goza la prensa, lo que no ocurre en caso de tratarse de particulares, más allá de la relevancia pública de lo que se denuncia (lo que también puede ser polémico en caso de no tratarse de un delito).

Adicionalmente, en cuanto al delito de injurias, el denunciante podría siempre argumentar que su propósito no era afectar el honor de la persona denunciada, sino poner en conocimiento de la autoridad (o, dado el caso, de los medios de comunicación) un asunto de interés público, por lo que no se verificaría el animus injuriandi, un elemento subjetivo que gran parte de la doctrina y jurisprudencia entienden exigido por el art. 416 del Código Penal. En este sentido, un caso interesante sobre el que se pronunció la Corte Suprema está relacionado con la revisión de una condena por delito de injurias de un habitante de Colonia Dignidad (comunidad de colonos alemanes localizada en la zona centro-sur de Chile en la que se descubrió la comisión de reiterados delitos contra la integridad física, psíquica y sexual de distintas personas, particularmente niños y adolescentes), que denunció haber sido víctima de diversos delitos a la Embajada de Alemania en Chile y a los medios de comunicación social, en la década de 1960, siendo condenado a sufrir una pena privativa de libertad de cinco años como culpable de injurias, que no terminaría cumpliendo en virtud de haber escapado del país. En el año 2016, el máximo tribunal revisó dicha condena y absolvió al denunciante, señalando entre otras cosas:

"En ese orden, los antecedentes ya reseñados demuestran que el actor a la sazón de sus dichos cuestionados por la sentencia en revisión actuó sin animus injuriandi, ya que las expresiones proferidas, acreditadas en el proceso, no tuvieron por objeto lesionar intencionadamente la honra de otros; sino informar a la población en general, y a la autoridad en particular, de los graves hechos que estaban ocurriendo en la llamada Colonia Dignidad, elemento sin el cual no puede estimarse que su obrar se subsuma en

\footnotetext{
${ }^{42}$ En FUENTES (2011), pp. 547-564, se expone con claridad la tensión que envuelve la existencia misma de un proceso penal para la conjugación entre el derecho a informar y el derecho al honor, sobre todo teniendo en consideración el respeto a la garantía de presunción de inocencia. Los alcances de los desafíos que presenta solucionar tal colisión de derechos puede proyectarse a la situación de una denuncia, más en casos en que, como se verá, se prefiera un canal externo e informal, como el de los medios de comunicación.

${ }^{43}$ Véase Corte Suprema, Rol N ${ }^{\circ} 22.162-2018$, de 28 de enero de 2019, c. $7^{\circ}$. Similar pronunciamiento en Corte Suprema, Rol N ${ }^{\circ} 18.748-2018$, de 23 de octubre de 2018, Rol N ${ }^{\circ} 17.732-2016$, de 24 de mayo de 2016 y Rol $\mathrm{N}^{\circ} 37.505-2015$, de 22 de febrero de 2016.
} 
el delito de injurias por ausencia de un elemento subjetivo adicional al dolo requerido por el respectivo tipo penal." 44

Sin necesidad de discutir sobre un determinado ánimo, menores dudas suscita la imputación de un delito falso, toda vez que se satisfarían los elementos del tipo de calumnia. Por su parte, la denuncia calumniosa del art. 211 del Código Penal, si bien podría verse como una especie de calumnia que se expresa en una acusación o denuncia formal, ha sido concebida como una figura que protege primeramente la administración de justicia. ${ }^{45}$ En cualquier modo, estas tipificaciones exigen la imputación de un delito, quedando excluidas las denuncias falsas de ilícitos que no alcancen relevancia penal.

En definitiva, lo que se ha pretendido dejar sentado en este apartado es que no existe una regulación específica que garantice la protección de un denunciante por medio de la creación de una justificación general que lo deje indemne frente a acusaciones criminales en su contra en las que se le impute la comisión de un delito por la denuncia misma. Tal cuestión queda relegada en Chile a la valoración que el tribunal realice casuísticamente según la ponderación de bienes jurídicos en juego, lo que constituye una posición de incertidumbre que no debe soslayarse.

\subsection{Ofrecimiento de atenuaciones o exención sancionatoria}

En la regulación chilena existen pocos casos en que se conceda la exención penal a una persona que, habiendo intervenido en la comisión de un delito, decida colaborar con las autoridades denunciando tal infracción. Uno de los ámbitos pioneros en esta materia es, como se dijo anteriormente (apartado 1), el Derecho de la libre competencia. En efecto, los programas de delación compensada han sido conocidos en Chile en el marco de la lucha administrativo-judicial contra los acuerdos colusorios. A su amparo se ofrece un incentivo a los partícipes en tales acuerdos, consistente en que si alguno pone término a su conducta y se presenta ante la autoridad confesando su responsabilidad y entregando antecedentes sobre los hechos y demás responsables, puede obtener una exención total de multa o una reducción de hasta el $50 \%$ de la misma, dependiendo de si se trata del primer o segundo delator (DL 211, art. 39 bis). La evaluación de esta institución por parte de las autoridades sectoriales (Tribunal de Defensa de la Libre Competencia y Fiscalía Nacional Económica) es muy positiva, toda vez que les ha permitido desbaratar diversos carteles que afectaron por largos períodos de tiempo a consumidores y competidores en distintos mercados.

Cuando en el año 2016 se decidió criminalizar la colusión, el legislador debió trasladar el beneficio de delación compensada también a la órbita penal con el fin de no restarle su efectividad. De esta manera, el primer delator puede acceder a una exención total de pena, mientras que el segundo podría beneficiarse de una atenuante (DL 211, art. 63). Un sistema similar, aunque con diversas condicionantes y limitaciones, se ha regulado a propósito de ilícitos que son conocidos por la Comisión para el Mercado Financiero. ${ }^{46}$

\footnotetext{
${ }^{44}$ Corte Suprema, Rol 89.658-201, de 23 de agosto de 2017, c. $8^{\circ}$.

45 Véase Corte Suprema, Rol No 31.572-2018, 6 de febrero de 2019; y Corte de Apelaciones de Santiago, Rol $\mathrm{N}^{\circ} 3.756-2018$, de 17 de agosto de 2018.

46 Véase Ley 21.000, art. 58.
} 
Más allá de estos casos, la colaboración del interviniente en un delito es también recompensada en contextos en los que existe un reconocimiento por parte del Estado de su impotencia para luchar contra entidades con complejas estructuras organizacionales que, si bien no imposibilitan, sí dificultan en extremo la investigación por parte de los órganos persecutores. Un caso paradigmático es el terrorismo, en el que la Ley 19.712, 1lamada "Ley sobre Arrepentimiento Eficaz", establece la exención de pena respecto de la asociación ilícita terrorista para aquellos que colaboren con la autoridad entregando información en las exigentes condiciones de oportunidad, forma y efectividad que dicha legislación establece. Además, la colaboración se reconoce también como una circunstancia atenuante en determinados casos, tanto en la misma materia de terrorismo (Ley 19.712, art. $2^{\circ}$ y Ley 18.314, art. $4^{\circ}$ ) como en el narcotráfico (Ley 20.000, art. 22). ${ }^{47}$ Fuera de los casos señalados, el comportamiento de un responsable que se decida a colaborar con la justicia solo podría reconducirse a un tratamiento más benigno mediante la aplicación de las circunstancias atenuantes genéricas del art. $11 \mathrm{n} .^{\circ} 7,8$ y 9 del Código Penal.

En enero de 2020 un grupo de parlamentarios ingresó a la Cámara de Diputados un proyecto de Ley que propone implementar el beneficio de la delación compensada para perseguir delitos cometidos en el marco de las protestas llevadas a cabo a partir de octubre de 2019. En particular, se plantea exonerar de responsabilidad a quienes, interviniendo en delitos de "incendio, amenazas, daños, saqueos, barricadas u obstrucción de tránsito" colaboren con el Ministerio Público, entregándole antecedentes que le permitan individualizar y detener a otros responsables. ${ }^{48} \mathrm{La}$ intención de los parlamentarios es dotar de mayores espacios de discrecionalidad al Ministerio Público en el ejercicio del principio de oportunidad, tal como existiría, según el proyecto de Ley, en los "delitos de terrorismo o colusión y libre competencia".

\section{Balance crítico y perspectivas para una futura regulación}

La regulación chilena vigente muestra algunas de las características de la regulación de esta misma materia en muchos otros países: en concreto, se advierte una regulación fragmentaria y sectorial, conformada por unas pocas normas jurídicas dispersas complementadas por algunas resoluciones judiciales. Se trata de un marco normativo que deja un amplio margen para la incertidumbre y que no parece especialmente apto para dar seguridad a una persona

\footnotetext{
${ }^{47}$ Un caso que puede vincularse con esta clase de delitos es la Ley 17.798 sobre control de armas, en la que el art. $14 \mathrm{C}$ contempla la exención de pena respecto de ciertas conductas delictivas, para aquellos casos de entrega voluntaria de armas a la autoridad antes de que haya mediado actuación policial, judicial o del Ministerio Público. Sin embargo, además de no tratarse de un caso de entrega de información, su fundamento parece obedecer a la naturaleza de delito de peligro que ostentan las conductas posesorias de armas, en las que, dado que el desistimiento no sería posible al no existir una distancia temporal entre el inicio de la ejecución y la consumación, se reconoce el comportamiento del agente de manera análoga al desistimiento de la tentativa. Al respecto, véase BASCUR (2017), pp. 594-595.

${ }^{48}$ Véase tramitación Boletín 13216-07, proyecto de Ley que "Modifica el Código Procesal Penal para eximir de responsabilidad penal, en las condiciones que señala, a quienes proporcionen antecedentes sobre los delitos contra el orden público que indica", en https://www.camara.cl/legislacion/ProyectosDeLey/tramitacion.aspx?prmID=13760\&prmBOLETIN=1321607 [última visita: 28-09-2020].
} 
que se proponga denunciar. En tal sentido, y como está sucediendo ya en otros países, si el legislador pretende dotar al ordenamiento jurídico chileno con una regulación moderna y adaptada a la creciente importancia de la figura será necesario valorar con detenimiento una serie de elementos que seguidamente se analizarán de manera individualizada.

\section{1. ¿Una regulación unitaria?}

Una primera opción que debe valorar el legislador es si conviene regular la figura del alertador en un único texto - creando algo así como un "estatuto del denunciante" — o bien si es mejor mantener regulaciones sectoriales a propósito de cada materia. Mientras en los Estados Unidos puede entenderse que predomina esta segunda perspectiva — propiciada en buena medida por el sistema federal - la Directiva europea parece poner las bases para que los estados miembros se decanten por un texto único en cada país, aunque está por ver cómo se concretará esta propuesta en los dos años de margen que tienen los legisladores nacionales para su transposición. Esta última opción parece claramente más adecuada si se pretende dar seguridad a los denunciantes, pues estos podrán encontrar todos sus derechos y deberes recogidos en un único texto legal. Pero es importante que la aprobación de dicho texto único se haga teniendo en cuenta el marco normativo previo, ya que una aprobación que previamente no depure el sistema jurídico de los elementos la regulación fragmentaria preexistente puede generar numerosas antinomias e inseguridad, tanto a denunciantes como a operadores jurídicos.

En Chile, como se ha expuesto, la situación para los denunciantes es distinta si se trata de funcionarios públicos o de empleados del sector privado. Respecto de los primeros, la normativa incorporada en virtud de la Ley 20.205 protege al denunciante de crímenes, simples delitos y cualesquiera hechos de carácter irregular, especialmente aquellos que contravienen el principio de probidad, por lo que se está en presencia de una regulación de aplicación bastante más amplia que aquella que guarda relación con los particulares. En efecto, respecto de estos últimos, no existe un estatuto de protección al whistleblower, por lo que su regulación se encuentra relegada a la coordinación de normas que, solo de manera tangencial, hacen referencia a dicha realidad, como las comentadas del Código Procesal Penal y del Código del Trabajo, y a pronunciamientos de los Tribunales que de alguna manera puedan vincularse al denunciante. Más aun, las iniciativas legislativas que proponen expresamente incorporar la figura del whistleblowing en Chile (como aquellas que se enmarcan en la "Agenda antiabusos" del Gobierno), profundizan el tratamiento sectorizado. Esto genera el insatisfactorio resultado de que pueda tratarse de manera distinta a una persona que realiza exactamente la misma conducta - denunciar - debido a la irregularidad que pone en conocimiento de la autoridad, sin que se evidencien razones claras para dicha diferencia. Un ejemplo claro, que se sigue de las comunicaciones públicas emitidas por el Gobierno, es que la recompensa sólo se ofrecería al denunciante de delitos financieros y no de corrupción o colusión.

El Proyecto de Ley del Denunciante, si bien apuesta aparentemente por la opción de la regulación unitaria (sean delitos o infracciones administrativas o disciplinarias), se queda corto en cuanto al ámbito en que estas denuncias recaigan: hechos en que tengan participación funcionarios u organismos de la Administración del Estado. Esta estrechez 


\section{Polít. Crim. Vol. 16, № 31 (Julio 2021), Art. 1, pp. 1-29 [http://politcrim.com/wp-content/uploads/2021/04/Vol16N31A1.pdf]}

genera problemas desde una perspectiva de igualdad, pues quien denuncie abusos y fraudes que hayan cometido empresas del sector privado no será merecedor de la protección especial que se pretende en el ámbito público. Si el objetivo es contar con un tratamiento más omnicomprensivo de los desafíos que significa darle protección a un denunciante de delitos e irregularidades, debería también considerarse la órbita de los delitos económicos cometidos desde la empresa privada. ${ }^{49}$

\section{2. ¿Protección administrativa o judicial?}

Como se ha expuesto anteriormente, el otorgamiento de un mayor nivel de protección ante posibles represalias es uno de los elementos fundamentales de cualquier reforma que pretenda incentivar las denuncias. Sin embargo, no está claro quién debe ser el responsable de reconocer su estatus a los denunciantes y velar por la aplicación de las correspondientes medidas de tutela. Dado que el denunciante no tiene por qué serlo únicamente de delitos, en algunos países se está optando por atribuir dicha función a organismos administrativos dotados de gran independencia funcional - en España, por ejemplo, las llamadas "agencias anticorrupción - con respecto al resto de la administración. La existencia de estas entidades, no obstante, puede plantear problemas competenciales con respecto a la autoridad judicial cuando el objeto de la denuncia sea un delito, ya que en tal caso es la administración de justicia quien cuenta con la información pormenorizada del caso. Por ello, si se opta por la creación de organismos administrativos es importante que se deslinden bien sus funciones y se establezcan criterios para evitar conflictos con la actuación judicial y sus mecanismos de tutela.

En Chile esta discusión, además, se entronca con otra que tiene que ver con la estructura del Estado y los diversos servicios públicos. El diseño institucional que en general se ha seguido durante, al menos, los últimos cuarenta años, es la creación de distintas agencias y superintendencias que se hacen cargo de un área muy específica, conformando una orgánica estatal profundamente atomizada. ${ }^{50}$ Esta situación hace que resulte complejo pensar en la creación de una única agencia que se haga cargo de recabar las denuncias ciudadanas que

${ }^{49}$ En este sentido, sería provechoso, por ejemplo, que a propósito de la discusión del proyecto de ley sobre delitos económicos al que se hizo referencia en nota al pie de página en el apartado 2.3.3, se aproveche el tratamiento global, uniforme y coherente que respecto a dicha naturaleza de criminalidad se pretende, para vincularla también a un estatuto de protección del denunciante. Reconociendo el avance que importa el Proyecto de Ley del Denunciante, MEDINA (2020), passim, quien, a la vez, también considera que podría ampliarse la cobertura del estatuto de protección al sector privado.

${ }^{50}$ En cuanto al desarrollo histórico y a una aproximación crítica en relación a esta conformación del Estado, véase PARDOW (2018), pp. 193-209. Dicho artículo expone que existirían en la historia reciente de Chile dos modelos distintos de reformas institucionales del Estado: uno, comenzado en la década de 1920 por la misión Kemmerer, de la cual surgieron instituciones con autonomía constitucional y con competencias técnicas y especializadas, pero de amplia cobertura, como el Banco Central y la Contraloría General de la República; y otro introducido en la década de 1980 por los Chicago Boys, del cual habrían surgido diversas agencias, formalmente independientes, que se hicieron cargo de la regulación y fiscalización de los diversos sectores económicos en que se había producido la privatización de servicios públicos. El autor argumenta su preferencia por el primer modelo. Con anterioridad, a propósito de comentarios al trabajo de la Comisión Engel, el mismo autor se había pronunciado sobre otro asunto relevante en relación a las potestades que se le entregan a entidades independientes, que tiene que ver con la coordinación entre estos agentes como condición para el éxito de las políticas públicas que se pretende implementar, en particular sobre mecanismos como la delación compensada o la recompensa al whistleblower, véase PARDOW (2015), pp. 281-286. 
guarden relación con irregularidades que puedan verificarse en diversos sectores de la economía. Un avance en la dirección del modelo centralizado es el Proyecto de Ley del Denunciante que regula la creación de un canal de denuncias que sea administrado por la Contraloría General de la República, el que, sin embargo, y como ya señalamos, sólo dice relación con infracciones cometidas en el seno de la Administración del Estado. Sería aconsejable revisar esta situación que, nuevamente, puede derivar en un trato desigual a personas que realizan similares denuncias solamente porque recaen en ámbitos distintos de la actividad económica. ${ }^{51}$

\subsection{Whistleblowing interno vs. whistleblowing externo}

Otra decisión importante que el legislador debe tomar en cualquier país es si, para reconocer el estatus de denunciante y la correspondiente tutela, debe exigirse al alertador que antes de acudir a las autoridades o a los medios de comunicación haya intentado ofrecer a su empresa la oportunidad de acometer una investigación interna y sancionar al responsable. En la Sarbanes-Oxley Act estadounidense se optaba por este modelo para facilitar que las compañías colaborasen con la justicia, pero posteriormente tal modelo ha sido muy criticado por ser excesivamente favorable a las empresas y facilitar reacciones poco elogiables, como destrucción de pruebas, amenazas a denunciantes, etc. De ahí que en la Dodd-Frank Act ya no se exigiera tal requisito. ${ }^{52}$ En la directiva europea se establece que los estados deberán "animar" a los trabajadores a intentar en primer término una denuncia ante su propia empresa, pero sin retirar de ningún modo la protección a quienes deciden saltarse dicho paso, especialmente cuando las expectativas de una reacción adecuada por parte de los máximos dirigentes corporativos sean mínimas (véase considerando 47 y art. 7.2)

En todo caso, con independencia del modelo por el que se opte deberá determinarse también si el hecho de contar con un procedimiento de denuncia interno debe elevarse al rango de obligación jurídica, o si es preferible continuar con la situación actual, en la que el procedimiento de denuncia es solo un elemento más a considerar en beneficio de la empresa -en sentido eximente o atenuatorio- en caso de que se le exija algún tipo de responsabilidad penal. Como se ha expuesto anteriormente (apartado 1), en el caso europeo todo apunta que en el caso de las empresas de un cierto tamaño (a partir de cincuenta empleados) se acabará imponiendo el modelo de la obligatoriedad.

\footnotetext{
${ }^{51}$ La creación de una entidad que se haga cargo de recabar las denuncias relativas a diversos ámbitos satisfaría el objetivo de aplicación uniforme de la normativa de whistleblowing que se recomienda en AGÜERO (2015), p. 10, para que el estatuto tenga eficacia. Además, se pueden desarrollar ideas, también presentes en el texto de este autor, tales como la de un examen de admisibilidad realizado por un abogado de la agencia estatal que certifique que se cumplen los requisitos de plausibilidad de la denuncia. En este sentido, y más allá de que el Proyecto de Ley del Denunciante se remita exclusivamente a la administración pública, debe reconocerse que, al menos en dicho ámbito, es un avance en cuanto a la uniformidad y homogenización del tratamiento de la materia.

${ }^{52}$ Sobre los pros y los contras de ambos modelos, ver RAGUÉS (2014), pp. 459-483.
} 


\section{Polít. Crim. Vol. 16, № 31 (Julio 2021), Art. 1, pp. 1-29 [http://politcrim.com/wp-content/uploads/2021/04/Vol16N31A1.pdf]}

\subsection{En relación con los incentivos concretos}

Finalmente, conviene analizar qué elementos hay que ponderar en relación con los concretos incentivos. Ya se ha adelantado (apartado 1), que no se aconseja la imposición de un deber general de denuncia, pero sería conveniente que se regulara con detalle - especialmente si se opta por crear un estatuto único del denunciante- con qué requisitos concretos el denunciante quedará protegido frente a cualquier tipo de reacción penal por parte de su empresa. Especialmente delicados son aquellos casos en los que el informante no solo se ha limitado a contar lo que sabía a las autoridades, sino que, para ser creído o evitar la destrucción de pruebas, ha sustraído documentación que hiciera más creíble su denuncia revelando secretos de la propia corporación o de terceros.

En materia de protección de denunciantes es importante revisar los tipos penales que protegen a los testigos de posibles represalias, a menudo pensados solo para preservar de amenazas de riesgos vitales a quienes están dispuestos a testificar en un procedimiento. Sin perjuicio de mantener estas figuras, conviene advertir que un denunciante no necesariamente es un testigo y que las represalias más frecuentes consisten en perjuicios de tipo laboral y no amenazas de muerte o lesiones. Algunos elementos de la directiva europea pueden resultar también de interés, por ejemplo, la citada inversión de la carga de la prueba cuando a una denuncia le sigue, poco tiempo después y sin otra explicación plausible, algún tipo de consecuencia negativa en el marco de la relación laboral. ${ }^{53}$ Asimismo, es pertinente considerar que la protección de identidad del denunciante o la admisión de denuncias anónimas, presentes en algunos proyectos para incorporar la figura del whistleblower en Chile, se encuentran sujetas a tensiones con el derecho de defensa y la presunción de inocencia. Ello comporta que estas declaraciones incriminatorias deben tener menor valor probatorio que una denuncia regular, una carencia que deberá ser debidamente compensada durante la investigación mediante la aportación de otros medios de prueba. ${ }^{54}$

En sentido inverso, y para evitar abusos, parece correcto que se prevea también un delito para sancionar las denuncias falsas, como lo hacen los proyectos de ley que pretenden incorporar la denuncia anónima o con reserva de identidad que fueron comentados anteriormente (apartado 2.3.1). Sin embargo, el legislador debe ser plenamente consciente de las limitaciones que el principio de legalidad impone en materia de criminalización. Sólo a modo ejemplar, los delitos que se proponen en el referido proyecto sancionarían a quien presente denuncia falsa de manera dolosa, dejando impune la denuncia falsa presentada de manera temeraria o mínimamente diligente en relación con la comprobación de los hechos por parte de quien denuncia. ${ }^{55}$ Además, el proyecto de ley que recae en el ámbito de infracciones anticompetitivas no considera casos en que, incluso obrando con dolo, el sujeto activo tenga

\footnotetext{
${ }^{53}$ Algún asomo de esta misma lógica, pero no con un tratamiento pormenorizado del denunciante, se encuentra en la norma del art. 493 del Código del Trabajo, tratado anteriormente (apartado 2.3.2) a propósito de la indemnidad y procedimiento de tutela laboral.

${ }^{54}$ Al respecto, véase RAGUÉS (2013), pp. 62-66.

55 Otra cuestión es si los delitos que se pretende incorporar admiten su configuración mediante dolo eventual. En este sentido, el proyecto de Ley que recae en el ámbito de libre competencia parece considerarlo, toda vez que sanciona a quien presente denuncia "a sabiendas, en antecedentes falsos o fraudulento con el propósito de perjudicar a otros agentes económicos". Sin embargo, el Proyecto de Ley del Denunciante utiliza el término "maliciosamente", el que suele ser asociado exclusivamente a dolo directo.
} 
por objeto perjudicar a un compañero de trabajo (pues la iniciativa sólo señala el propósito de perjudicar a otros agentes económicos).

Las recompensas económicas y la plena exención punitiva al denunciante-infractor plantean dudas más serias. Las primeras, como ya se ha expuesto, generan algunas reservas que, aun siendo de naturaleza cultural, no cabe ignorar de entrada: en tal sentido, conviene tener presente que los sistemas políticos que a lo largo de la historia han optado por incentivar las denuncias ciudadanas no han sido precisamente ejemplares, por lo que se impone en este ámbito un cierto principio de precaución basado en la experiencia histórica, que aconseja no acudir a los estímulos más intensos hasta que no se constate el fracaso de los más moderados.

Precisamente por este motivo, también hay que observar con ciertos recelos la exención total de sanción a los colaboradores con la justicia, especialmente porque en tales casos los incentivos para generar información falsa son elevados y quien paga las consecuencias de ello suele ser otro acusado. Además, el solo hecho de otorgar un beneficio consistente en la exención de pena a un responsable por la comisión del delito tensiona los fundamentos del Derecho Penal. ${ }^{56}$ Por lo tanto, este recurso debería limitarse en el caso de que se optara por él- a contextos específicos de criminalidad y estar sujeto a exigencias muy estrictas en cuanto a la verificabilidad de las pruebas aportadas. Ninguno de estos requisitos se cumple en relación al proyecto de ley que fuera comentado anteriormente (apartado 2.4), que pretende incorporar la delación compensada para delitos comunes en el contexto de las protestas ciudadanas acontecidas en Chile en 2019. Finalmente, si se opta por atribuir valor eximente a ciertas delaciones sería conveniente dotar a la figura del acusado-testigo de un rol particular, reduciendo las posibilidades, por ejemplo, de negarse a contestar las preguntas de las defensas.

\section{Valoración final}

En resumen: si, como parece, el legislador chileno mantiene en los próximos años su apuesta por incentivar las denuncias, será necesario que valore con detenimiento todos los anteriores puntos para lograr que las correspondientes reformas guarden coherencia sistemática y resulten asumibles por un sistema que pretende ser respetuoso con los derechos fundamentales. De otro modo se corre el peligro de que este instrumento devenga un recurso perturbador desde el punto de vista institucional, populista pero poco efectivo políticocriminalmente e inquietante desde la perspectiva de las garantías.

\footnotetext{
${ }^{56}$ En efecto, la idea de eximir de pena al responsable colaborador con la justicia ha sido cuestionada desde una perspectiva axiológica y valorativa, reprochándose, entre otras cosas, el hecho de que, al plantearse como un premio a la deslealtad, no satisfaría los fines de la pena y, además, vulneraría el principio de igualdad, toda vez que, por regla general, sería un beneficio disponible para quienes han tenido mayor responsabilidad por el acaecimiento del delito, quienes están en mejores condiciones de aportar información relevante a la autoridad. Para una descripción detallada de estos reproches, véanse varios autores (RODRÍGUEZ (2018), passim; y SÁNCHEZ GARCÍA (2005), passim.
} 


\section{Referencias bibliográficas}

AGÜERO, Francisco (2015): Minuta: Propuesta de whistleblower para la detección de prácticas de corrupción y otros ilícitos (Santiago, Centro de Regulación y Competencia).

AUBERT, Cecile; REY, Patrick; KOVACIC, William (2006): "The impact of leniency programs on cartels", en: International Journal of Industrial Organization (Vol. 24, $\mathrm{N}^{\circ}$ 6), pp. 1241-1266.

BARAHONA, Jaime; LEITON, Alejandra (2020): "Nuevas reformas para fortalecer la persecución de carteles", en: Investigaciones CeCo (junio). Disponible en: https://tinyurl.com/yg4vstxx [visitado el 20/07/2020].

BASCUR, Gonzalo (2017): “Análisis de los principales delitos y su régimen de sanción previsto en la Ley N ${ }^{\circ} 17.798$ sobre Control de Armas", en: Política Criminal (Vol. $\left.12, \mathrm{~N}^{\circ} 23\right)$, pp. 533-609.

BENITO, Demelsa (2019): "The European Union Criminal Policy against Corruption: Two Decades of Efforts", en: Política Criminal (Vol. 15, N²7), pp. 520-548.

CALLAHAN, Elletta Sangrey; DWORKIN, Terry Morehead (1992): "Go Good and Get Rich: Financial Incentives for Whistleblowing and the False Claims Act", en: Villanova Law Review (37), pp. 276-336.

CALLAHAN, Elletta Sangrey; DWORKIN, Terry Morehead; LEWIS, David (2003-2004): "Whistleblowing: Australian, U.K., and U.S. Approaches to Disclosure in the Public Interest", en: Virginia Journal of International Law (880), pp. 879-912.

CONSEJO ASESOR PRESIDENCIAL CONTRA LOS CONFLICTOS DE INTERÉS, EL TRÁFICO DE INFLUENCIA Y LA CORRUPCIÓN (2015): "Informe Final". Disponible en: https://tinyurl.com/yz93xeu2 [visitado el 28/09/2020].

DUCE Mauricio (2020): “¿La revolución de mayo? La Corte Suprema y los controles de identidad", en: El Mercurio Legal (9 de junio). Disponible en: https://tinyurl.com/yzlb2suu [visitado el 20/07/2020].

FELDMAN, Yuval; LOBEL, Orly (2010): "The Incentives Matrix: The Comparative Efectiveness of Rewards, Liabilities, Duties, and Protection for Reporting Illegality", en: Texas Law Review (88), pp. 1151-2011.

FUENTES, María Fernanda (2011): "El derecho a la honra como límite a la libertad de información hasta el momento de la acusación penal", en: Revista de Derecho de la Pontificia Universidad Católica de Valparaíso (XXXVII), pp. 547-564.

GARCÍA-MORENO, Beatriz (2020): Del Whistleblower al alertador. La regulación europea de los canales de denuncia (Valencia, Tirant lo Blanch).

GUERRA, Sandra (2002): “The White-Collar Police Force: 'Duty to Report' Statutes in Criminal Law Theory", en: William \& Mary Bill of Rights Journal (3), pp. 3-65.

GUTIÉRREZ, Elena (2018): "Corrupción pública: concepto y mediciones. Hacia el Public compliance como herramienta de prevención de riesgos penales", en: Política Criminal (Vol. 13, $\mathrm{N}^{\circ}$ 25), pp. 104-143.

HEFENDEHL, Roland (2009): "Alle lieben Whistleblowing", en: BÖSE, Martin; STERNBERG-LIEBEN, Detlev (Eds.), Grundlagen des Straf- und Strafverfahrensrechts. Festschrift für Knut Amelung zum 70. Geburtstag (Berlín, Duncker \& Humblot), pp. 617-643. 
HORZELLA, Bárbara (2019): "Mecanismos de denuncia y protección al denunciante de irregularidades en las Fuerzas Armadas. Marco regulatorio nacional y experiencia comparada, informe elaborado para la Comisión de Defensa Nacional”. Disponible en: https://tinyurl.com/yf9xqtfe [visitado el 20/07/2020].

LEE, Jenny (2011-2012): “Corporate Corruption \& the New Gold Mine”, en: Brooklyn Law Review (77), pp. 303-339.

MEDINA (2020), Gonzalo: "La protección del denunciante de actos contra la probidad administrativa", en: El Mercurio Legal $\left(1^{\circ}\right.$ de julio). Disponible en: https://tinyurl.com/yk4haekn [última visita: 06-07-2020].

NAVAS, Iván; JAAR, Antonia (2018): "La responsabilidad penal de las personas jurídicas en la jurisprudencia chilena", en: Política Criminal (Vol. 13, N 26), pp. 1027-1054.

OCDE (2012): "Whistleblowing Protection: encouraging reporting, Iniciativa 'CleanGovBiz"”. Disponible en: https://tinyurl.com/yzbxe2eh [visitado el 20/07/2020].

ORTIZ, Juan Carlos (2018): Los delatores en el proceso penal (Madrid, Wolters Kluwer).

PARDOW, Diego (2018): “¿Control o autonomía? El debate sobre agencias regulatorias independientes", en: Revista de Derecho, Universidad Austral de Chile (Vol. 31, N $^{\circ}$ 2), pp. 193-209.

PARDOW, Diego (2015): "Atribuciones para una fiscalización eficaz de los mercados (Capítulo IV.a.; pp. 84-86)", en: Revista de Derecho, Universidad Austral de Chile (Vol. 28, N²), pp. 281-286.

PELLEGRINI, Julio; RAMOS, Diego (2020): “Comentarios al Proyecto de Ley que fortalece la investigación y persecución de carteles y que aumenta las penas para delitos de colusión", en: Investigaciones $\mathrm{CeCo}$ (mayo). Disponible en: https://tinyurl.com/yg4vstxx [visitado el 20/07/2020].

PIMSTEIN, María Elena (2019): "Obligación de denunciar y secreto de confesión". Disponible en: https://tinyurl.com/yfga6ncq [visitado el 20/07/2020].

QUIGLEY, Shannon (2012): "Whistleblower Tug-Of-War: Corporate attempts to secure internal reporting procedures in the face of external monetary incentives provided by the Dodd-Frank act”, en: Santa Clara Law Review (52), pp. 255-296.

RAGUÉS, Ramon (2020): "El tratamiento jurídico de los denunciantes antes y después de la Directiva 2019/1937”, en: La Ley Compliance Penal (1), pp. 1-13.

RAGUÉS, Ramon (2015): "La trascendencia penal de la obtención y revelación de información confidencial en la denuncia de conductas ilícitas", en: InDret (3), pp. 134.

RAGUÉS, Ramon (2014): "El fomento de las denuncias como instrumento de política criminal contra la criminalidad corporativa: whistleblowing interno vs. whistleblowing externo", en: MIR, Santiago; CORCOY, Mirentxu; GÓMEZ, Víctor (Dirs.): Responsabilidad de la empresa y compliance (Madrid, Edisofer - BdeF), pp. 459-483.

RAGUÉS, Ramon (2013): Whistleblowing. Una aproximación desde el Derecho penal (Madrid, Marcial Pons).

RAPP, Geoffrey (2007): "Beyond Protection: Invigorating Incentives for Sarbanes Oxley Corporate and Securities Fraud Whistleblowers", en Boston University Law Review (87), pp. 91-156. 
RODRÍGUEZ, Víctor (2018): Delaçao premiada. Limites éticos ao Estado (Río de Janeiro, EditoraForense)

SÁNCHEZ GARCÍA, María Isabel (2005): "El coimputado que colabora con la Justicia penal", en: Revista Electrónica de Ciencia Penal y Criminología ( $\left.\mathrm{N}^{\circ} 7\right)$. Disponible en: http://criminet.ugr.es/recpc/07/recpc07-05.pdf [visitado el 07.04.2021].

VANDEKERCKHOVE, Wim; TSAHURIDU, Eva (2010): "Risky Rescues and the Duty to Blow the Whistle”, en: Journal of Business Ethics (Vol. 97), p. 372.

VERGARA, Alejandro (2020): "Tutela laboral de funcionarios públicos: sorprendente giro jurisprudencial de la Corte Suprema", en: El Mercurio Legal (11 de febrero). Disponible en: https://tinyurl.com/yflftubj [visitado el 20/07/2020].

\section{Jurisprudencia citada}

Corte Suprema, Rol N ${ }^{\circ} 31.572-2018$, de 6 de febrero de 2019

Corte Suprema, Rol No 22.162-2018, de 28 de enero de 2019.

Corte Suprema, Rol No 18.748-2018, de 23 de octubre de 2018.

Corte de Apelaciones de Santiago, Rol N ${ }^{\circ} 3.756-2018$, de 17 de agosto de 2018.

Corte Suprema, Rol 89.658-201, de 23 de agosto de 2017.

Corte Suprema, Rol N ${ }^{\circ} 17.732-2016$, de 24 de mayo de 2016.

Corte Suprema, Rol No 1.806-2015, de 8 de marzo de 2016.

Corte Suprema, Rol No 37.505-2015, de 22 de febrero de 2016.

Corte Suprema, Rol No 8.393-2012, de 21 de agosto de 2013. 